\title{
Is lutein a physiologically important ligand for transthyretin in humans?
}

\author{
by
}

\section{Liwei Chen}

\author{
A thesis submitted to the graduate faculty \\ in partial fulfillment of the requirements for the degree of \\ MASTER OF SCIENCE
}

Major: Nutrition

Program of Study Committee:

Wendy White, Major Professor

Mark Kaiser

Manju Reddy

Louisa Tabatabai

Iowa State University

Ames, Iowa

2003

Copyright (C) Liwei Chen, 2003. All rights reserved. 
ii

Graduate College

Iowa State University

This is to certify that the master's thesis of Liwei Chen

has met the thesis requirements of Iowa State University
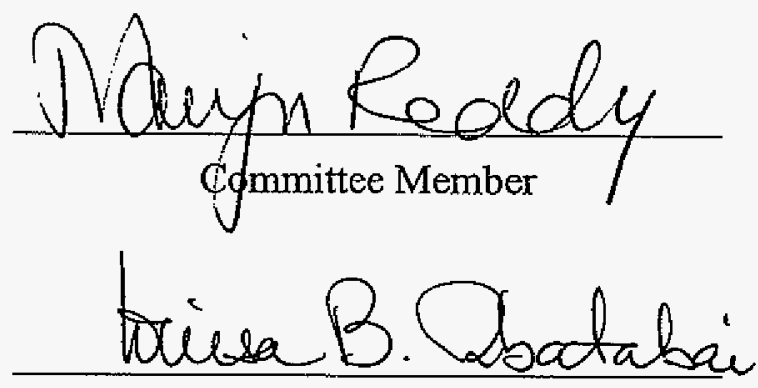

Committee Member
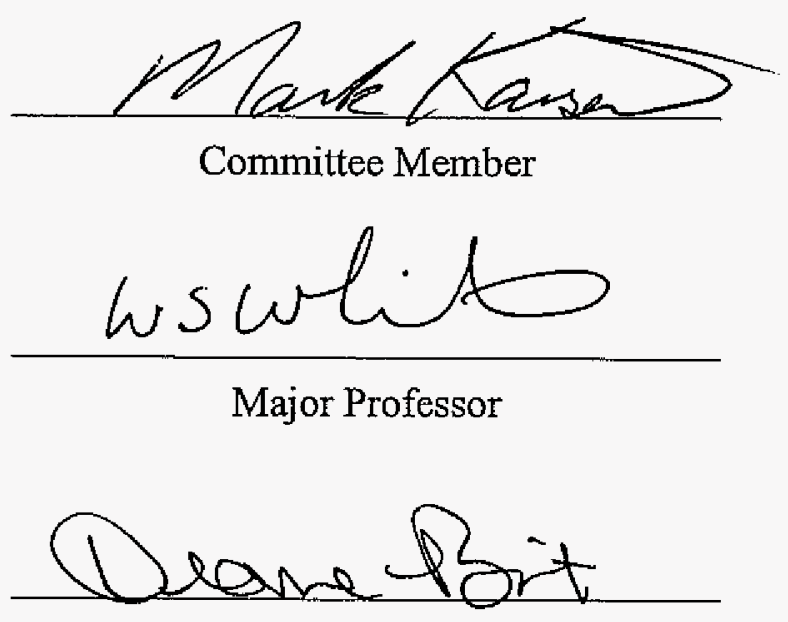

For the Major Program 
TABLE OF CONTENTS

$\begin{array}{lc}\text { ABSTRACT . } & \text { iv } \\ \text { CHAPTER 1. GENERAL INTRODUCTION } & 1 \\ \text { CHAPTER 2. MATERIALS AND METHODS } & 12 \\ \text { CHAPTER 3. RESULTS } & 29 \\ \text { CHAPTER 4. DISCUSSION } & 44 \\ \text { CHAPTER 5. CONCLUSION } & 51 \\ \text { CHAPTER 6. ACKNOWLEDGEMENTS } & 53 \\ \text { CHAPTER 7. REFERENCES } & 54 \\ \text { APPENDIX } & 69\end{array}$




\section{ABSTRACT}

Lutein and zeaxanthin are the only carotenoids accumulated in the macula of the human retina and are known as the macular pigments (MP). These pigments account for the yellow color of the macula and appear to play an important role in protecting against agerelated macular degeneration (AMD). The uptake of lutein and zeaxanthin in human eyes is remarkably specific. It is likely that specific transport or binding proteins are involved. Our objective is to determine whether transthyretin (TTR) is a transport protein in human plasma and could thus deliver lutein from the blood to the retina. In this study, we used a biosynthetic ${ }^{13} \mathrm{C}$-lutein tracer and gas chromatography-combustion interfaced-isotope ratio mass spectrometry (GCC-IRMS) to gain the requisite sensitivity to detect the minute amounts of lutein expected as a physiological ligand for human transthyretin. The biosynthetic ${ }^{13} \mathrm{C}$-labeled lutein tracer was purified from algae. Healthy women $(n=4)$ each ingested $1 \mathrm{mg}$ of ${ }^{13} \mathrm{C}$-labeled lutein daily for 3 days and a blood sample was collected 24 hours after the final dose. Plasma TTR was isolated by retinol-binding protein (RBP)sepharose affinity chromatography and extracted with chloroform. The ${ }^{13} \mathrm{C} /{ }^{12} \mathrm{C}$ ratio in the TTR extract was measured by GCC-IRMS. There was no ${ }^{13} \mathrm{C}$-lutein enrichment in the pure TTR extract. This result indicated that lutein is not associated with TTR in human plasma after ingestion in physiological amounts. Some hydrophobic compounds with yellow color may bind to human TTR in the plasma. However, this association needs to be further proved by showing specificity. Our study provides a new approach for carotenoid-binding protein studies using a stable isotope tracer method combined with the high precision of GCC-IRMS. 
The mechanism of selective transport, uptake, and accumulation of lutein in human macula remain to be determined. 


\section{INTRODUCTION}

\section{Age-related macular degeneration (AMD)}

Age-related macular degeneration (AMD) is the leading cause of irreversible blindness among older people in Western counties. It occurs in $19.7 \%$ of the population over 65 in the U.S. (1). By the year 2025, an estimated 25.7 million people age 45 and older will have signs of $\operatorname{AMD}(2,3)$. AMD is a progressive disease involving degeneration of the retinal pigment epithelium (RPE) and photoreceptor in the macular region. The macula is the small central part of retina. It is a slightly oval region of approximately $2-3 \mathrm{~mm}$ horizontal diameter that is centered on the fovea, where the visual axis meets the retina. The region has a yellow color which is only found in the primate retina and gives the macula a common name of yellow spot (macula lutea). Despite its small size, this region projects onto a large area of the visual cortex and has the highest density of cone photoreceptor which makes the macula functionally responsible for central vision and visual acuity. In AMD patients, changes of decreased density and/or uneven distribution of macular pigment (MP) (early AMD) with the degeneration of RPE cell and decline the number of photoreceptors (advanced AMD) are usually found $(4,5)$. These changes affect the function of the macula and result in loss of central vision and visual acuity. Activities essential for independent living, including reading, driving, writing, and recognizing familiar faces are impaired. The quality of life of elderly people is severely affected by AMD, so there is high motivation to prevent this disease. However, despite the significance of this disease, there is no available means to prevent it, and effective treatment is limited to only a small fraction of patients (5, 6). The lack of effective interventions to prevent or treat AMD has made it one of the most frustrating diseases commonly encountered in ophthalmologic practice. 
The pathogenesis of AMD is still not clearly understood. The major known risk factors for AMD: cigarette smoking, sunlight exposure, and low ocular melanin, probably related the pathogenesis to oxidative processes $(1,7,8)$. Various insults that include normal metabolic processes within cells and possibly photochemical damage from ultraviolet and high-energy visible light (blue light) can initiate the oxidative process in the eye (9-11). The formation of free radicals and highly reactive singlet oxygen caused by these insults can lead to lipid peroxidation $(7,10)$. The high concentrations of polyunsaturated fatty acids in the photoreceptor outer-segment membranes and high exposure to blue light make the macula particularly vulnerable to these affects (11). These insults may cause damage, incompletely degraded molecules, impaired function of the retinal pigment epithelium, and, theoretically, could lead to degeneration involving the macula.

\section{Macular pigments}

Lutein and zeaxanthin are two dietary carotenoids which are found in normal human plasma and accumulated in high amount in the retina macular region known as the macular pigments (MP) $(12,13)$. These pigments account for the yellow color of the macula. Extensive work has shown that lutein and zeaxanthin are deposited specifically in the photoreceptor axon layer (Henle's fibers), the inner plexiform layer, and rod outer segment with zeaxanthin more concentrated in the foveal center and lutein spread more diffusely throughout the retina (13-16). The concentrations of the macular pigment rise remarkably to almost $1 \mathrm{mM}$ in the central macula (17). This corresponds to more than 3 -fold the concentration in normal serum and 500-fold the concentration in other tissues (17). This type of distribution implies that there must be a system to specifically take up, concentrate and 
store exclusively lutein and zeaxanthin in the macula while excluding other carotenoids such as $\beta$-carotene and lycopene which are also abundant in the blood.

These macular pigments appear to be especially important for normal macular function. The acuity hypothesis is the most long-standing although unproven hypothesis. It proposes that MP may decrease the adverse effects of the chromatic aberration in the ocular media by absorbing the poorly focused short-wavelength light, thereby increasing visual acuity (1821). More recently, it is believed MP may protect against light-induced damage to the retina by filtering harmful bright short-wavelength light, or functioning as an antioxidant within the retina, or both (22-26).

\section{AMD and lutein}

Several large epidemiological studies suggested that dietary factors, particularly antioxidants, may have protective effects against $\operatorname{AMD}(9,27,28)$. Seddon et al (1994) investigated the relationship between dietary carotenoids, vitamins $\mathrm{A}, \mathrm{C}$ and $\mathrm{E}$, and $\mathrm{AMD}$ in both patients and controls 55 to 80 years of age. Those in the highest category of lutein and zeaxanthin intake were $57 \%$ less likely to have advanced AMD (29). A protective role of Iutein in preventing AMD is also suggested by research indicating that lower plasma lutein concentration and/or lower MP density are associated with higher risk of AMD. Macular pigment was depleted in monkeys fed diets deficient in lutein and zeaxanthin (30). Maintenance on such diets for up to 14 years resulted in retinal changes including loss of RPE cells and photoreceptor cells which are similar to the pathologic changes of AMD. Human studies have also investigated the relation of plasma and macular lutein levels with the risk of AMD. The Eye Disease Case Control Study (EDCCS) Group compared the fasting serum samples of 615 control and 412 patients recently diagnosed with AMD. Those 
with lutein/zeaxanthin concentration $\geq 0.67 \mu \mathrm{mol} / \mathrm{L}$ were $70 \%$ less likely to have AMD than those with concentration $\leq 0.25 \mu \mathrm{mol} / \mathrm{L}(9)$. An autopsy study found that macula from patients with a history of AMD had lower concentrations of MP relative to control eyes from patients without a known history of AMD (31). Hammond et al. in 1998 showed a positive relationship between MP density and visual sensitivity (32). Bone et al (2001) compared the MP concentrations of retinas from 56 donors with AMD to those without AMD. The results suggested that individuals with low lutein and zeaxanthin in their retinas are at greater risk of acquiring AMD (33).

A large body of evidence indicates that both plasma concentration and MP density can be modified by diet. Nutritional studies have demonstrated that increased consumption of foods or supplements rich in lutein and zeaxanthin elevated serum levels of these carotenoids and in many cases resulted in increased serum lutein concentration and MP density (34-38). In addition, several recent studies reported improvements of visual function (e.g., higher contrast sensitivity, higher glare sensitivity, improved color perception, and improved visual acuity) in some AMD patients with lutein supplementation (39-41). In contrast, several other studies found no consistent association between lutein and AMD. Mares-Perlman et al reported that there is no significant association between lutein and zeaxanthin intake and AMD in a retrospective study, The Beaver Dam Eye Study (42). Mares-Perlman et al. (1995) also found no significant differences in the mean non-fasting serum lutein concentrations in AMD cases and controls (43). However, the range of serum concentrations of lutein and zeaxanthin in this study was not as great as that observed in the Eye Disease Case Control Study (EDCCS). Similar results were also observed by Vanden Langenberg (44) and Sanders (45). 


\section{Lutein and its metabolism}

Lutein and zeaxanthin are the only carotenoids accumulated in the macula of the human retina $(12,13)$. It is also well established that peripheral retina and lens are enriched in these carotenoids $(14,46,47)$. In addition, Bernstein et al (1999) reported that quantifiable levels of lutein, zeaxanthin, their geometrical $(\mathrm{E} / \mathrm{Z})$ isomers, and their metabolites were found in other ocular tissues (iris, ciliary body) (48). The uptake of lutein and zeaxanthin in human eyes is remarkably specific because many other prominent serum carotenoids such as $\alpha$ carotene, $\beta$-carotene, $\beta$-cryptoxanthin, and lycopene have not been found in eye tissues. Lutein and zeaxanthin are structural isomers (Figure 1). They are more polar than many other carotenoids and have hydroxyl groups on the cyclic end rings. The hydroxyl groups may allow them to incorporate into the cell membrane in an orientation that stabilizes the membrane. The only structural distinction between Iutein and zeaxanthin is the placement of one double bond. The allylic hydroxyl of lutein is much more easily oxidized than the secondary hydroxyl groups present in zeaxanthin $(49,50)$. The normal Western diet contains 1-2 mg/day of lutein (51). Lutein is found in the diet in larger quantities than zeaxanthin. It has been estimated that the ratio of lutein to zeaxanthin in the diet ranges from about $4: 1$ to $7: 1(52,53)$. In human serum, like the diet, lutein dominates over zeaxanthin. The ratio of lutein to zeaxanthin ranges from 2.7 to $4.5: 1$ and depends upon diet and individual characteristics such as genetics and lifestyle (54-57). Therefore lutein is thought to be the more essential carotenoid. 
<smiles>CC1=C(/C=C/C(C)=C/C=C/C(C)=C/C=C/C=C(C)/C=C/C=C(C)/C=C/C2=C(C)C[C@@H](O)CC2(C)C)C(C)(C)C[C@H](O)C1</smiles>

\section{Zeaxanthin}

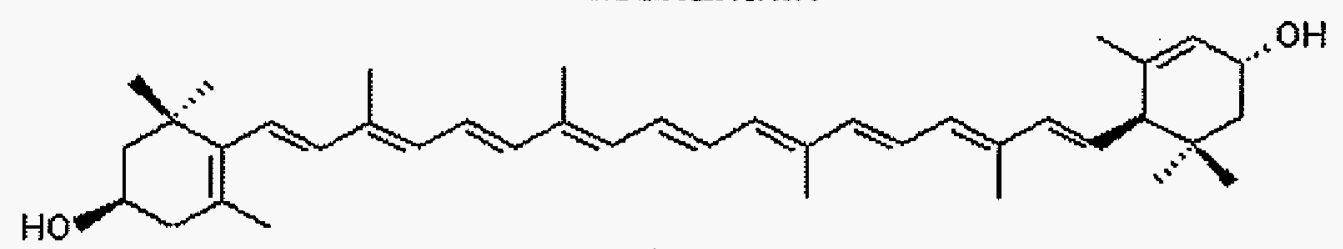

Lutein

Figure 1. Chemical structures of lutein and zeaxanthin.

Despite the putative importance of lutein in human health, many aspects of the absorption and metabolism of lutein and other carotenoids are not well understood. The biochemical mechanisms that mediate the selective uptake, concentration, and stabilization of the macular pigment are unknown. Why does the retina accumulate lutein and zeaxanthin to the exclusion of other carotenoids, such as $\beta$-carotene and lycopene, which are abundant in the blood? Why have some epidemiological and nutritional studies failed to find a relation between serum concentrations of lutein and zeaxanthin and risk of AMD? To answer these questions, more detailed information on lutein metabolism is needed. To our understanding, when a tissue exhibits highly selective uptake of a chemical compound, it is likely that specific transport and/or binding proteins are involved. Hence it is reasonable to hypothesize that there is a lutein-binding protein family present in human plasma and retina to transfer lutein from the diet via blood to the retina and mediate the uptake and accumulation of the high concentrations of lutein and zeaxanthin in human eye. Any interindividual differences 
in this delivery system would help to explain the inconsistent results from previous studies. More importantly, abnormalities in this hypothetical delivery system would have profound effects on macular function and could be involved in the pathogenesis of AMD.

Carotenoid-binding proteins in plants and invertebrates have been purified and extensively studied. The plant and algal proteins are usually involved in photosynthesis or photoprotection $(58,59)$. $\alpha$-Crustacyanin is a $350 \mathrm{kDa}$ astaxanthin-binding protein responsible for the color of lobster shells (60). A lutein-binding protein that may be involved in the specific uptake of dietary lutein in the midgut of the silkworm has been purified and partially characterized by Jouni and Wells (61). This protein has a molecular weight of 35 $\mathrm{kDa}$ but the amino acid sequence has not been defined. The lutein-protein complex is water soluble and more stable than lutein or protein alone. Preliminary data suggests that lutein binds to the hydrophobic sites of the protein.

Much less is known about carotenoid-binding proteins in vertebrates. A $67 \mathrm{kDa}$ soluble $\beta$-carotene-bind protein was isolated from ferret liver by Rao et al. (62), but the sequence was not reported. This protein prefers binding to carotene over xanthophylls. Bernstein et al. (63) reported that retinal tubulin, a $55 \mathrm{kDa}$ water soluble protein abundant in the photoreceptor axon layer, binds macular carotenoids in bovine. In the same study, soluble extracts of human macula were also partially purified. HPLC analysis showed that endogenous lutein and zeaxanthin copurified with tubulin. However, binding affinity studies using bovine brain tubulin indicated that many carotenoids, including $\beta$-carotene, can bind to tubulin. Hence it is unlikely that tubulin is the mediator protein accounting for the specific uptake of macular pigments unless cone tubulin has a particularly high affinity and specificity for lutein and zeaxanthin. Recently, two human retinal membrane-associated 
proteins, xanthophyll-binding proteins (XBP), which contain two major proteins bands at 25 $\mathrm{kDa}$ and $55 \mathrm{kDa}$ have been partially purified and show strong and specific binding affinity for macular lutein and zeaxanthin with little or no affinity for other carotenoids (64). Comparison of XBP to other potential mammalian carotenoids-binding proteins (tubulin, lactoglobulin and serum lipoproteins) using the peak $\mathrm{A}_{460} / \mathrm{A}_{280}$ ratios showed that only XBP exhibited a high specificity for lutein and zeaxanthin. It is likely that membrane associated $\mathrm{XBP}$ plays a role in mediating the uptake of lutein and zeaxanthin in human retina. However, further purification and characterization need to be performed in order to provide stronger evidence. In human plasma, low-density lipoproteins (LDL) and high-density lipoproteins (HDL) are the major carriers of carotenoids (65). Lutein and zeaxanthin are evenly distributed between HDL and LDL while $\beta$-carotene and lycopene are preferentially carried by LDL (65-67). However, HDL and LDL do not specifically bind lutein and/or zeaxanthin, and there is no HDL or LDL receptor founded in the human retina. Thus these two lipoproteins could not be responsible for the selective delivery of lutein and zeaxanthin from the blood to the retina. Pettersson et al. (68) reported that lutein is associated with transthyretin (TTR) in chicken plasma. This was the first report that lutein is associated with TTR. The finding of specific binding of lutein to chicken TTR may offer a functional role for TTR in the retina.

\section{Transthyretin (TTR)}

Transthyretin (TTR) is a multifunctional protein found in the plasma in many species. The structure of TTR is well conserved throughout evolution (69). Human TTR (previously called prealbumin) occurs in human plasma as a tetramer composed of apparently identical subunits each of $14 \mathrm{kDa}$ molecular weight $(70,71)$. The two well-established functions of 
human TTR are transport of thyroxine (72) and transport of retinol (vitamin A) via the retinol-RBP-TTR complex (73). But other functions have been considered. In plasma, retinol is bound to retinol-binding protein (RBP; MW 21,000) which is associated with TTR in 1:1 molar ratio. This transport complex serves to solubilize the hydrophobic retinol molecule and stabilize the retinol-RBP and protect RBP during glomerular filtration $(74,75)$. RBP receptors are present on the basal and lateral membranes of the RPE cells (76). Retinol is transported to the retinal pigment epithelium (RPE) cell by the RBP-TTR complex and may enter the RPE cell without RBP (77). In the RPE cell, retinol is esterified and then carried to the photoreceptors by an interphotoreceptor retinal-binding protein (IRBP) (78). Retinol is transported by IRBP between RPE and photoreceptors as part of the visual cycle that regenerates the visual pigments after they have absorbed light and triggered electrical signals.

TTR is primarily synthesized in the liver (79). But the synthesis of TTR is also been found in several extrahepatic sites such as central nervous system and eye. Several studies reported that TTR is synthesized and secreted by the choroids plexus epithelium (80-82) but the precise role of TTR within the central nervous system has not yet been determined. In the eye, TTR has widespread distribution in a variety of ocular cells such as RPE, ciliary epithelium, iris epithelium, corneal endothelium, and lens capsule (83). However mRNAs of TTR are only found in the retinal pigment epithelium (RPE) cell (84). Then RBP was reported to be synthesized in the RPE cell by Herbert et al. (85). Ong et al. (1995) confirmed that both TTR and RBP can be synthesized and secreted by cultured RPE cells, and it is found that the secretion ratio of TTR to RBP was as high as 50:1 (86). The function of ocular TTR and RBP are unknown. It was proposed that they may play a role in the 
intraocular processing of retinol (83). It is also likely these proteins involved in the delivery of all-trans-retinol to amacrine and Müller cells as a precursor for retinoic acid since these cells are know to have cellular retinoic acid binding protein (87). TTR might be serving some function in the retina which is unrelated to its ability to form a complex with RBP given its extremely high expression in the RPE. Notably, in Pettersson's study (68), association of lutein is a specific finding for TTR, as no lutein could be identified in similar extracts of chicken RBP. Also, the binding seems to be specific for lutein, as none of the other common carotenoids were found to be associated with TTR. These results provide a potential explanation for the selective accumulation of lutein in the macula if lutein is associated with TTR and transported from the bloodstream to the RPE via RBP-TTR complex or TTR alone. Emstrom (88) also identified a yellow pigment associated with human TTR but it was not lutein. Their results showed that the major yellow component extracted from human TTR had properties similar to a pterin derivative. However, there are two major limitations in Ernstrom's human study. First, chickens are fed rations supplemented with lutein as a source of broiler and yolk pigmentation (89). This results in serum lutein concentrations in chickens that are 20 -fold higher than in humans. The human retina contains only 5-40 ng lutein concentrated within the macula (24). Hence conventional HPLC analysis may not detect the low amount of lutein expected to be bound to TTR in unsupplemented subjects. In Ernstrom's study, the investigators used acidic methanol in the extraction of the yellow component from the TTR fraction. The, acidic methanol is not a good solvent for carotenoid extraction. The acid may cause lutein degradation. We hypothesized that use of a milder extraction protocol and more sensitive instrument would overcome these limitations in Pettersson's study. 
Gas chromatography combustion-isotope ratio mass spectrometry (GCC-IRMS) and its application in carotenoid research

High-precision gas isotope ratio mass spectrometry (IRMS) is the classical technique for determination of isotope ratio due to natural processes for $\mathrm{C}, \mathrm{H}, \mathrm{N}, \mathrm{O}$, and $\mathrm{S}(90)$. In the 1900s, gas chromatography (GC) was interfaced to IRMS by a microcombustion furnace (91). This new technology, GCC-IRMS, enabled high-precision stable carbon isotope analysis of individual, volatile organic compounds in chemically complex samples separated by GC. With its character of high sensitivity and capability for stable isotope analysis, GCCIRMS enables a unique tracer approach for carotenoid research (91). Since carotenoids are mainly ingested in the diet and no animal model can be used to replace the human, a stable isotope tracer method is often essential for study of carotenoid metabolism in humans. With GCC-IRMS, we are able to administer a physiological dose of carotenoid and avoid the health risks of radioactive material.

Several studies have used GCC-IRMS to investigate the metabolism of $\beta$-carotene and lutein in humans (92-95). We showed that application of this technique to study of lutein metabolism requires the conversion of lutein to a thermally-stable perhydro analog $(94,95)$. The catalytic hydrogenation of lutein and acid-catalyzed removal of the hydroxyl groups produces the major product perhydro- $\beta$-carotene ( $\mathrm{m} / \mathrm{z} 558.6)$ and secondary products (95). The secondary products have mass spectra at $\mathrm{m} / \mathrm{z} 574.4$ and $\mathrm{m} / \mathrm{z} 572.6$ that are consistent with saturated and monounsaturated forms of anhydrolutein, a product which most likely results from the favored acid-catalyzed dehydration of the allylic hydroxyl group of lutein (96). 
In this study, we will use a biosynthetic ${ }^{13} \mathrm{C}$-lutein tracer and gas chromatographycombustion interfaced-isotope ratio mass spectrometry (GCC-IRMS) to gain the requisite sensitivity to detect the minute amounts of lutein expected as a physiological ligand for human transthyretin. Our overall objective is to achieve a detailed understanding of the role of lutein in ocular health. The specific aim for this study is to determine whether lutein is associated with TTR in human plasma and the extent to which lutein is bound to TTR. We expect that our study will help to understand the mechanism responsible for the selective uptake and concentration of lutein in the macula. This mechanism could be used to increase the density of the macular pigment and, potentially, to prevent the progressive blindness caused by age-related macular degeneration.

\section{MATERIALS AND METHODS}

1. Human metabolic methods: Study protocols were approved by the Human Subjects Review Committee of Iowa State University.

\subsection{Subjects}

Healthy female nonsmokers $(n=4) 19$ to 38 years of age were selected based on interview, anthropometric assessment (height and weight, body mass index), and normal complete blood count, including hemoglobin and hemocrit. Subjects had blood hemoglobin concentration greater than $125 \mathrm{~g} / \mathrm{L}$ as measured at the Iowa State University Student Health Center within a 7-day period preceding blood donation for the study. Criteria for exclusion included current or recent cigarette smoking; frequent alcohol consumption ( $>1$ drink/day); recent use of medications that may affect lipid absorption or transport (including antibiotics); use of multivitamin, lutein, beta-carotene, or other carotenoid supplements during the 
previous 3 months; aversion to phlebotomy or the sight of blood; whole blood donation within 8 weeks preceding scheduled blood donation for the study; history of anemia or excessive bleeding; history of macular degeneration or other eye diseases, chronic diseases, lipid malabsorption or gastrointestinal disorders, lactose intolerance, abnormal thyroid status, photosensitivity; atypical food habits (e.g., severe ređucing diet, anorexic diet, hypercarotenemic diet, vegetarian diet); atypical body weight (i.e., less than 120 pounds or greater than $130 \%$ of the mean weight for height and age); current or planned pregnancy, menstrual cycle irregularities or abnormalities (including heavy menstrual periods), use of oral contraceptives.

\subsection{Study diet}

Subjects were instructed to avoid dietary supplements, fruits, and vegetables with a high content of lutein for a 3-week period preceding the dosing protocol. The intent was to deplete serum transthyretin of lutein originating from the diet in order to maximize saturation of the transthyretin with lutein originating from the test doses.

\section{$1.3{ }^{13} \mathrm{C}$-Lutein dosing protocol}

Subjects ingested an emulsion prepared with banana $(30 \mathrm{~g})$, fat-free milk $(70 \mathrm{~mL})$, and high oleic sunflower oil (28 g, purchased from Abitec Corporation, Janesville, WI, USA) which contained $1.0 \mathrm{mg}$ of ${ }^{13} \mathrm{C}$-labeled lutein (95). Subjects ingested the emulsion each day under observation over a 3-day period in the Human Metabolic Unit in the Center for Designing Food to Improve Nutrition at Iowa State University. The $1.0 \mathrm{mg}$ daily dose of lutein simulates the average daily intake of lutein in the U.S. population (51).

\subsection{Blood collection}

Each subject donated $500 \mathrm{~mL}$ of blood for isolation of transthyretin $24 \mathrm{~h}$ after 
ingestion of the third and final dose of ${ }^{13} \mathrm{C}$-labeled lutein. Blood was collected in the Human Metabolic Unit of the Center for Designing Food to Improve Nutrition by an experienced registered nurse employed as a phlebotomist at the local blood bank. A clinical assessment including blood pressure, pulse, and body temperature was performed for each subject immediately before and after the blood donation. Exclusion criteria included systolic blood pressure less than 100 or higher than $180 \mathrm{~mm} \mathrm{Hg}$, pulse less than 50 or higher than 100 per minute, and body temperature higher than $37.2^{\circ} \mathrm{C}$. Subjects donated $500 \mathrm{~mL}$ of blood while supine. Standard phlebotomy technique for whole blood donation was used. A $600 \mathrm{~mL}$ Baxter Fenwal Transfer Pack Container (Baxter Heather Corporation, Deerfield, IL, USA) and a Terumo Surflo Winged Infusion Set (Terumo, Corporation, Tokyo, Japan) were used to collect the blood during donation. Each subject was required to remain supine for a minimum of $10 \mathrm{~min}$ and was then shifted to a seated position for at least 5 min. The subjects were then instructed to drink at least 8 ounces of apple juice to replace lost blood volume.

Subjects were permitted to leave the Human Metabolic Unit 10 minutes later if asymptomatic. Blood was taken to the Blood Bank of Mary Greeley Hospital (Ames, IA) to separate the plasma. The individual plasma samples were stored at $-70^{\circ} \mathrm{C}$ until used for isolation of transthyretin.

\section{Tracer $\left({ }^{13} \mathrm{C}\right.$-lutein) preparation}

Purified ${ }^{13} \mathrm{C}$-labeled lutein is not commercially available. Crude lipid extract from algae grown under an environment of ${ }^{13} \mathrm{C}$ labeled $\mathrm{CO}_{2}$ was purchased from Martek Bioscience Inc (Columbia, $\mathrm{MD}, \mathrm{USA}$ ). In the algae, all components were uniformly-labeled with ${ }^{13} \mathrm{C}$. The carotenoid composition of the crude lipid extract was determined by high performance liquid chromatography (HPLC) to be $65 \%$ lutein, $30 \% \beta$-carotene, and $5 \%$ unidentified carotenoids. 
In order to purify lutein, $200 \mathrm{mg}$ of crude algal extract were transferred to a $50-\mathrm{mL}$ screwcapped glass test tube. $25 \mathrm{~mL}$ of acetone (HPLC grade) were added and mixed, followed by vortexing for $2 \mathrm{~min}$. The mixture was centrifuged $(2000 \mathrm{rpm} \times 10 \mathrm{~min})$. The upper acetone layer was carefully removed. This extraction process was repeated until the yellow color of the paste/acetone mixture almost disappeared. The acetone extracts were combined and dried under argon to a volume of $50 \mathrm{~mL}$ and then transferred to a separatory funnel. $80 \mathrm{~mL}$ of hexane was added to the funnel. Then $30 \mathrm{~mL}$ of distilled water was carefully added to the funnel until the acetone and hexane layer were clearly separated. The acetone and water layer was discarded. The upper hexane layer was washed with $30 \mathrm{~mL}$ of water in the separatory funnel. After discarding the water, $80 \mathrm{~mL}$ of methanol and water ( $95: 5$ by vol) were added to the funnel to partition the lutein from the hexane. Without shaking, the lower methanol and water layer was collected and transferred to another separatory funnel. An equal volume of ethyl ether was added to the funnel. Then water was added until two layers formed. The lower methanol and water mixture were discarded. The upper ethyl ether layer was then divided equally among four 50 - $\mathrm{mL}$ screw-capped glass test tubes. Water $(5 \mathrm{~mL})$ was added to each tube, mixed, and centrifuged at $2000 \mathrm{rpm}$ for $30 \mathrm{~min}$. The ethyl ether fractions was combined and dried under vacuum. The dried residue was then dissolved with $4 \mathrm{~mL}$ of hexane. The mixture was vortexed and transferred to a microfiltration apparatus. Hexane $(100 \mathrm{~mL})$ was added to the funnel to wash the residue continuously during the filtration. After drying, the red product on the filter paper was transferred to a 5-mL screwcapped glass vial. Warm methanol $(2 \mathrm{~mL})$ was added to redissolve the red product. The vial was heated until the solution was clear. The methanol solution was allowed to cool to room temperature. Hexane $(2 \mathrm{~mL})$ was then added to the vial drop wise and with shaking. The 
vial was then filled with argon and stored at $-20^{\circ} \mathrm{C}$ overnight for crystallization. The methanol solution containing the red lutein crystals was transferred to the microfiltration apparatus. The cumulative product of 5 to 7 days was combined to avoid losses resulting from use of a small quantity during the operation. The lutein crystals were washed with 50 $\mathrm{mL}$ of hexane. The product was left in the dark in a fume hood for $8 \mathrm{~h}$ to allow the solvent to evaporate. The final product was stored in a small glass vial under argon in the dark at $-80^{\circ}$ C. By using this protocol, approximatelyl $\mathrm{mg}$ of lutein was purified from $200 \mathrm{mg}$ of crude algal extract.

3. Purify TTR and RBP from outdated human plasma (All operations were carried out in a cold room at $4^{\circ} \mathrm{C}$. The isolation method was modified based on a protocol generously provided by Dr. David Ong, Vanderbilt University.)

\subsection{Plasma sample preparation}

Outdated human plasma was generously donated by the Blood Bank of Mary Greeley Hospital (Ames, IA). One liter of plasma was filtered though a $1 / 4$-in bed of celite to remove lipid. Then the plasma was divided among 10 segments of dialysis membrane tubing (Spectrum Medical, Inc, Los Angeles, CA, USA) with MWCO of 6000 to 8000 and dialyzed against $5 \mathrm{~L}$ of $0.05 \mathrm{M}$ phosphate buffer $\mathrm{pH} 7.4$ containing $0.05 \mathrm{M} \mathrm{NaCl}$. The dialysis was

extended to $16 \mathrm{~h}$ and the buffer was changed 4 times during this period $\left(1^{\text {st }}\right.$ hour, $2^{\text {nd }}$ hour, $3^{\text {rd }}$ hour, and $15^{\text {th }}$ hour).

\subsection{Saturate the RBP with all-trans-retinol}

All-trans-retinol was purchased from Sigma Chemical (St. Louis, MO, USA). A stock solution of $1 \mathrm{mg} \mathrm{retinol} / \mathrm{mL}$ in ethanol was prepared according to the instructions of the supplier. The concentration of retinol solution was determined using a molar extinction 
coefficient of 46000 at $330 \mathrm{~nm}$. The retinol stock solution was stored at $-20^{\circ} \mathrm{C}$ under

nitrogen in a brown glass vial. Immediately before use, the retinol stock solution was diluted by dimethylsulfoxide (DMSO) to about $5 \times 10^{-4} \mathrm{M}$. The freshly made DMSO solution was added to the dialyzed plasma using a glass pipette. An equimolar amount of retinol to retinol-binding protein was used. The mixture was incubated for $30 \mathrm{~min}$ for at room temperature in the dark. The plasma was then centrifuged at $10000 \times \mathrm{g}$ for $30 \mathrm{~min}$ to remove any precipitate.

\subsection{Ion exchange chromatography (DEAE column)}

The DEAE column $(2.5 \times 22 \mathrm{~cm})$ was packed in our lab with DE 52 (Whatman International Ltd, Maidstone, Kent, England). The clear plasma supernatant was applied to the DEAE column which had been equilibrated with 10 bed volumes of dialysis buffer. The eluate was monitored with an ISCO UA-6 absorbance detector (ISCO, Inc, Lincoin, NE, USA) set at $280 \mathrm{~nm}$. After the plasma was pumped onto the column, it was washed with $0.05 \mathrm{M}$ phosphate buffer $\mathrm{pH} 7.4$ containing $0.05 \mathrm{M} \mathrm{NaCl}$ until there was no absorbance at $280 \mathrm{~nm}$. Immediately after the wash, elution was carried out with a linear gradient of $\mathrm{NaCl}$ from $0.05 \mathrm{M}$ to $0.5 \mathrm{M}$ in $0.05 \mathrm{M}$ phosphate buffer, $\mathrm{pH} 7.4$. Fractions of $5 \mathrm{~mL}$ were collected by using a CF-1 Fraction Collector (Spectrum Chromatography, Huston, TX, USA) at a flow rate of $70 \mathrm{~mL} / \mathrm{h}$. A total of 100 tubes were collected and tested for absorbance at $280 \mathrm{~nm}$, $330 \mathrm{~nm}$, and $400 \mathrm{~nm}$ by using a Hewlett Packard-8452A Diode Array Spectrophotometer (Boehringer Mannheim, Indianapolis, IN, USA). Fluorescence (exc $335 \mathrm{~nm}$, ext $460 \mathrm{~nm}$ ) was also measured for all tubes using a Waters 474 Scanning Fluorescence Detector (Waters Corporation, Milford, MA, USA). Fractions with both fluorescence and UV absorbance 
were pooled and saved. This combined fraction contained the retinol-binding protein (RBP)transthyretin (TTR) complex.

\subsection{Ammonium sulfate precipitation}

The fraction containing the pooled RBP-TTR complex was reduced in volume to $100 \mathrm{~mL}$ by using an Amicon Ultrafiltration Cell (Amicon, Inc, Beverly, MA, USA) with a YM-3 filter (Millipore Corporation, Bedford, MA, USA) under nitrogen pressure. The sample was then precipitated with $1.5 \mathrm{M}$ ammonium sulfate and $2 \mathrm{M}$ citric acid was used to adjust the $\mathrm{pH}$

to 6.0 . The solution was allowed to stand overnight. It was centrifuged at $10000 \times \mathrm{g}$ for 10 min and the supernatant was saved.

\subsection{Hydrophobic interaction chromatography (phenyl-sepharose column)}

The phenyl-sepharose column $(2.5 \times 33 \mathrm{~cm})$ was packed in our lab with phenylsepharose CL-4B purchased from Sigma. The clear supernatant obtained from the ammonium sulfate precipitation was applied to the phenyl-sepharose column which had been equilibrated with 10 bed volumes of $0.05 \mathrm{M}$ citrate buffer $\mathrm{pH} 6.0$ containing $1.5 \mathrm{M}$ ammonium sulfate. Fractions of $10 \mathrm{~mL}$ were collected at a flow rate of $120 \mathrm{~mL} / \mathrm{h}$. Immediately after loading the protein sample, elution was started with a linear gradient from the starting buffer to $0.03 \mathrm{M}$ phosphate buffer, $\mathrm{pH} 7.0(1500 \mathrm{~mL})$. Fractions were tested for absorbance at $280 \mathrm{~nm}, 330 \mathrm{~nm}$, and $400 \mathrm{~nm}$ as described above. Two protein fractions were detected. The TTR fraction comprised a large peak between tubes 50 and 120 . The RBP fraction was eluted before tube 150 . These fractions distributed among multiple collection tubes were pooled in 3 to 4 tubes for further use.

\subsection{Ion exchange chromatography $\left(2^{\text {nd }}\right.$ DEAE column: $\left.2.5 \times 30 \mathrm{~cm}\right)$}

The fraction (about $150 \mathrm{~mL}$ ) containing TTR was dialyzed overnight against $0.05 \mathrm{M}$ 
Tris-acetate buffer, $\mathrm{pH}$ 8.3. The buffer was changed 4 times. The dialyzed protein sample was then applied to a $2^{\text {nd }}$ DEAE column which had been equilibrated with the dialysis buffer. Fractions of $5 \mathrm{~mL}$ were collected at a flow rate of $60 \mathrm{~mL} / \mathrm{h}$. Fractions were tested for protein absorbance as above. The major peak (peak 2) which contained TTR was pooled and concentrated using the YM3 membrane in the Amicon Ultrafiltration Cell. The concentrated sample was stored in several tubes at $-80^{\circ} \mathrm{C}$ until used for packing the affinity column.

\subsection{Preparation of the TTR-sepharose affinity column}

\section{(1) Couple TTR with the affinity media}

Human TTR was isolated in our lab from outdated plasma as described above. The protein was concentrated and dialyzed using a Micro ProDiCon CE membrane (Spectrum, Houston, TX, USA) in a Micro-ConFilt Vacuum Dialysis Unit (Bio-Molecular Dynamics, Beaverton, Oregon, USA) generously loaned by Dr. Barbara Wiggert, Laboratory of Retinal Cell and Molecular Biology, National Eye Institute, Bethesda, MD, USA. 0.1 M NaHCO3 buffer containing $0.5 \mathrm{M} \mathrm{NaCl}, \mathrm{pH} 8.3$ was used as dialysis buffer. $\mathrm{CNBr}$-activated Sepharose 4B was obtained from Amersham Pharmacia Biotech (Piscataway, New Jersey, USA). A desired amount of freeze-dried powder of $\mathrm{CNBr}$-activated Sepharose 4B was weighed ( $1 \mathrm{~g}$ freeze-dried powder gives $4-5 \mathrm{~mL}$ drained gel). The powder was transferred to a screw-capped glass centrifuge tube and suspended in $1 \mathrm{mM} \mathrm{HCl}$ for at least $30 \mathrm{~min}$. The resin and $\mathrm{HCl}$ mixture were then centrifuged at low speed (3000 rpm) for $5 \mathrm{~min}$. The supernatant was removed by pasteur pipette and additional $1 \mathrm{mM} \mathrm{HCl}$ was added followed by shaking. The mixture was then centrifuged again as above. The wash with $\mathrm{HCl}$ was repeated 2 more times. A total of $200 \mathrm{~mL}$ of $1 \mathrm{mM} \mathrm{HCl}$ was needed to swell and wash $1 \mathrm{~g}$ powder. The $\mathrm{HCl}$ supernatant was discarded and 10 volumes of deionized water were added 
to the tube. The sample was then mixed and centrifuged at $3000 \mathrm{rpm}$ for $5 \mathrm{~min}$. The aqueous supernatant was removed and about 5 bed volumes of coupling buffer $(0.1 \mathrm{M}$ $\mathrm{NaHCO}_{3}$ containing $0.5 \mathrm{M} \mathrm{NaCl}, \mathrm{pH} 8.3$ ) were added to the resin. The mixture was centrifuged to remove the supernatant. Protein solution (protein in coupling buffer) was added to the gel immediately (about 5-10 mg protein per $\mathrm{mL}$ of gel). Protein and gel were mixed in a glass tube by rotating overnight at $4{ }^{\circ} \mathrm{C}$. The excess ligand was washed away with 5 bed volumes of coupling buffer. The unreacted groups were then blocked by adding 1 $\mathrm{M}$ ethanolamine, pH 8 . The block reaction was carried out at $4{ }^{\circ} \mathrm{C}$ for at least $16 \mathrm{~h}$. The blocking solution was then washed extensively with a cycle of 10 bed volumes of cold deionized water followed with 10 bed volumes of coupling buffer 5 times. The washings were collected and concentrated. The binding ability of the TTR and ligand was approximately $96 \%$ during the coupling procedure.

\section{(2) Pack the TTR-sepharose affinity column}

The slurry was degassed under vacuum before packing and then pulled into an empty glass column purchased from Bio-Rad (Bio-Red Laboratories, Hercules, CA, USA). The column was allowed to settle followed by equilibration with $0.01 \mathrm{M}$ PBS buffer containing $0.5 \mathrm{M} \mathrm{NaCl}, \mathrm{pH} 7.4$ at a flow rate of $2.5 \mathrm{~mL} / \mathrm{min}$. The column was stored at $4{ }^{\circ} \mathrm{C}$ with $2 \mathrm{mM}$ sodium azide added to the buffer. In our study, $35 \mathrm{mg}$ of TTR was coupled with the CNBractivated Sepharose $4 B$ affinity media to pack a $5 \mathrm{~mL}(1.5 \times 3.0 \mathrm{~cm})$ TTR-sepharose affinity column.

\subsection{Purify the retinol-binding protein using the TTR-sepharose affinity column}

RBP sample was partially purified using the phenyl-sepharose column described above. The sample was dialyzed using a Slide-A-Lyzer Dialysis Cassette (Pierce, Rockford, IL, 
USA) with $0.01 \mathrm{M}$ PBS buffer containing $0.5 \mathrm{M} \mathrm{NaCl}, \mathrm{pH} 7.4$. The dialyzed sample was applied to our TTR-sepharose affinity column $(1.5 \times 3.0 \mathrm{~cm})$ which had been equilibrated with the dialysis buffer. Fractions of $2 \mathrm{~mL}$ were collected and the flow rate was adjusted to $1.0 \mathrm{~mL} / \mathrm{min}$. After the sample was pumped onto the column followed by $1 \mathrm{~mL}$ of starting buffer, the flow was stopped for $20 \mathrm{~min}$ to ensure the binding of RBP to the gel matrix. The column was then washed with 3 bed volumes of starting buffer followed with 3 bed volumes of $0.01 \mathrm{M}$ PBS (no NaCl). The RBP fraction was eluted with deionized water. The pure RBP from several runs was pooled and concentrated by the Vacuum Dialysis Unit. The concentrated RBP was stored at $-80^{\circ} \mathrm{C}$ under argon.

\subsection{Couple RBP with CNBr-activated sepharose 4B and pack a RBP-sepharose affinity} column

The coupling and packing procedures were the same as described above. In our study, 11 $\mathrm{mg}$ RBP was used to pack an affinity column $(1.0 \times 2.5 \mathrm{~cm})$.

4. Purify TTR from subject's plasma (Unless otherwise indicated, procedures were carried out under yellow light at $4^{\circ} \mathrm{C}$ )

\subsection{Method 1: Isolate RBP-bound TTR from human plasma.}

\section{(1) Plasma sample preparation}

A subject's plasma $(250 \mathrm{~mL})$ was filtered though a $1 / 4$-inch bed of celite to remove lipid. Then the plasma was transferred to 3 sections of dialysis membrane tubing (Spectrum Medical, Inc) with MWCO of 6000 to 8000 . The plasma was dialyzed against $0.05 \mathrm{M}$ phosphate buffer $\mathrm{pH} 7.4$ containing $0.05 \mathrm{M} \mathrm{NaCl}$. The dialysis was extended to $16 \mathrm{~h}$ and the buffer was changed 4 times during this period $\left(1^{\text {st }}\right.$ hour, $2^{\text {nd }}$ hour, $3^{\text {rd }}$ hour, and $15^{\text {th }}$ hour$)$. 
Then the plasma was centrifuged at $10000 \times \mathrm{g}$ for $30 \mathrm{~min}$ to remove any precipitate. The clear supernatant was saved for loading onto the DEAE column.

\section{(2) Ion exchange chromatography (DEAE column: $2.5 \times 22 \mathrm{~cm}$ )}

The plasma sample was applied to a 100-mL DEAE column which had been equilibrated with $0.05 \mathrm{M}$ phosphate buffer $\mathrm{pH} 7.4$ containing $0.05 \mathrm{M} \mathrm{NaCl}$. After all the plasma was pumped onto the column, the column was washed with the starting buffer (about $200 \mathrm{~mL}$ ) until there was no absorbance at $280 \mathrm{~nm}$. Immediately after the wash, elution was carried out with a linear gradient $(500 \mathrm{~mL})$ of $\mathrm{NaCl}$ from $0.05 \mathrm{M}$ to $0.5 \mathrm{M}$ in $0.05 \mathrm{M}$ phosphate buffer,

$\mathrm{pH}$ 7.4. Fractions of $5 \mathrm{~mL}$ were collected at a flow rate of $70 \mathrm{~mL} / \mathrm{h}$. 100 tubes were collected and tested for absorbance of $280 \mathrm{~nm}, 330 \mathrm{~nm}, 400 \mathrm{~nm}$ and also fluorescence (exc $335 \mathrm{~nm}$, ext $460 \mathrm{~nm}$ ). Fractions containing TTR-RBP complex which had both UV absorbance and fluorescence were pooled and saved. For multiple uses, the DEAE column was cleaned and regenerated using the following protocol recommended by the manufacturer: (1) Wash the column with 2 bed volumes of $0.5 \mathrm{M} \mathrm{NaOH}$ and allow it to stand for $12 \mathrm{~h}$ at room temperature; (2) Wash the column with 2 bed volumes of demineralized water; (3) Wash the column with 2 bed volumes of $0.5 \mathrm{M}$ phosphate buffer, $\mathrm{pH}$

\section{(3) Ammonium sulfate precipitation}

The fraction containing RBP-TTR complex was reduced in volume to $50 \mathrm{~mL}$ by using an Amicon Ultrafiltration Cell with YM-3 filter under nitrogen pressure. The sample was then precipitated with $1.5 \mathrm{M}$ ammonium sulfate and $2 \mathrm{M}$ citric acid was used to adjust the $\mathrm{pH}$ to 6.0. The protein solution was allowed to stand overnight. It was then centrifuged at $10000 \times$ $\mathrm{g}$ for $10 \mathrm{~min}$ and the supernatant was saved.

(4) Hydrophobic interaction chromatography (phenyl-sepharose column: $1.5 \times 30 \mathrm{~cm}$ ) 
The $50 \mathrm{~mL}$ clear supernatant from the ammonium sulfate precipitation was applied to a 53-mL phenyl-sepharose column which had been equilibrated with 10 bed volumes of 0.05 $\mathrm{M}$ citrate buffer $\mathrm{pH} 6.0$ containing $1.5 \mathrm{M}$ ammonium sulfate. Fractions of $10 \mathrm{~mL}$ were collected at a flow rate of $0.72 \mathrm{~mL} / \mathrm{min}$. Immediately after loading the protein sample, elution was started with a linear gradient from the starting buffer to $0.03 \mathrm{M}$ phosphate buffer, pH $7.0(600 \mathrm{~mL})$. Fractions were tested for absorbance at $280 \mathrm{~nm}, 330 \mathrm{~nm}$ and $400 \mathrm{~nm}$.

Fractions containing RBP were pooled, concentrated, and saved at $-80^{\circ} \mathrm{C}$. The TTR faction was concentrated to about $20 \mathrm{~mL}$ using the Amicon Ultrafiltration Cell and then further purified with the affinity column (see below). For optimal results, the column was stored in $20 \%$ ethanol at $4^{\circ} \mathrm{C}$ after each use.

\section{(5) Affinity Chromatography}

The TTR fraction from the phenyl-sepharose column was dialyzed against the 0.01 M PBS buffer $\mathrm{pH} 7.4$ containing $0.5 \mathrm{M} \mathrm{NaCl}$. The dialyzed sample was applied to our RBPSepharose affinity column $(1.0 \times 2.5 \mathrm{~cm})$ which has been equilibrated with the dialysis buffer. Fractions of $2 \mathrm{~mL}$ were collected and the flow rate was adjusted to $1.0 \mathrm{~mL} / \mathrm{min}$. When the entire sample had been pumped onto the column and followed by $1 \mathrm{~mL}$ of starting buffer, the flow was stopped for $20 \mathrm{~min}$ to ensure the binding of TTR to the gel. The column was then washed with 3 bed volumes of starting buffer followed with 3 bed volumes of 0.01 M PBS (no NaCl). The TTR was eluted with at least 8 bed volumes of deionized water. The pure TTR was concentrated by the vacuum dialysis unit until a final volume of $0.5 \mathrm{~mL}$ was obtained. The $0.5 \mathrm{~mL}$ TTR sample was then removed from the membrane tube. The membrane was washed with PBS buffer 3 times, $0.5 \mathrm{~mL}$ each time. The washings were 
combined with the $0.5 \mathrm{~mL}$ TTR to obtain a final TTR sample of $2 \mathrm{~mL}$. The sample was saved in a brown vial at $-80^{\circ} \mathrm{C}$ under argon.

\subsection{Method 2: Isolate both free TTR and RBP-bound TTR}

\section{(1) Ammonium sulfate precipitation}

To a $100-\mathrm{mL}$ aliquot of plasma from each subject, $19.8 \mathrm{~g}$ of ammonium sulfate was slowly added to give a final concentration of $1.5 \mathrm{M}$. The $\mathrm{pH}$ was adjusted to 6.0 by $2 \mathrm{M}$ citric acid. The protein solution was allowed to stand overnight. The protein solution was then centrifuged at $10000 \times \mathrm{g}$ for $10 \mathrm{~min}$ and the supernatant was saved.

(2) Hydrophobic interaction chromatography (phenyl-sepharose column: $2.5 \times 33 \mathrm{~cm}$ )

A $100-\mathrm{mL}$ of the clear protein solution obtained from the ammonium sulfate precipitation was applied to the phenyl-sepharose column using the procedure described above. The only differences were that a $1500 \mathrm{~mL}$ buffer gradient was used in here because of the big column size, and I-mL fractions were collected. Fractions were tested for absorbance at $280 \mathrm{~nm}, 330$ $\mathrm{nm}$, and $450 \mathrm{~nm}$. Three peaks were isolated by this chromatography. These fractions were concentrated and analyzed by diode array spectrophotometer for absorbance spectra and by SDS-PAGE for purity. Peak 1 which contained TTR was reduced to $5 \mathrm{~mL}$ in volume.

\section{(3) Affinity chromatography}

$5-\mathrm{mL}$ aliquots of the concentrated TTR fraction from the peak 1 were each purified by affinity chromatography using the procedure described above. The purity of the TTR fractions was analyzed by SDS-PAGE. The pooled pure TTR fractions were concentrated by the Vacuum Dialysis Unit to a final volume of $2 \mathrm{~mL}$. 


\section{SDS-PAGE and immunoblotting}

We performed SDS-PAGE analysis of protein fractions using the NuPage pre-cast $12 \%$ Bis-Tris gels with appropriate buffers. A XCell SureLock Mini-Cell, NuPage Bis-Tris gel (10 wells), NuPage MOPS SDS Running Buffer, NuPage LDS Sample Buffer, and NuPage Antioxidant were purchased from Invitrogen (Invitrogen Corporation, Carlsbad, CA, USA). Gels were stained using Brilliant Blue G Concentration from Sigma. Immunoblotting was done using a BA83 Pure Nitrocellulose Transfer and Immobilization membrane (Schleicher\& Schuell, Inc., Keene, NH, USA). The Mini Trans-Blot Electrophoretic Transfer Cell, and Tris/Glycine Transfer Buffer were obtained from Bio-Rad. A Power PAC 200 power supply were generously loaned by Dr. Manju Reddy, Department of Food Science and Human Nutrition. Perfect Protein AP Western Blot Kits was obtained from Novagen (CN Biosciences, Inc, Madison, WI, USA). Prealbumin (N-19, sc-8105) and Bovine anti-goat Ig G (sc-2351) were obtained from Santa Cruz (Santa Cruz Biotechnology, Santa Cruz, CA, USA). Rabbit Anti-Human Retinol-Binding Protein (RBP) and Alkaline PhosphataseConjugated Goat Anti-Rabbit Immunoglobins were purchased from DAKO (DAKO Corporation, Carpinteria, CA, USA). BCIP/NBT Phosphatase Substrate was obtained from KPL (KPL, Inc, Gaithersburg, MD, USA). Pure human TTR and RBP were purchased from

Sigma. The protocols used for SDS-PAGE and immunoblotting were kindly provided by Dr. T. Michael Redmond, National Eye Institute, Bethesda, MD. Please see appendix.

\section{Protein concentration}

The protein concentration in the crude and purified samples was measured by the Bradford Method. Bradford reagent was purchased from Sigma. $10-\mu 1$ protein samples were pipetted onto a 96-well microplate. $10 \mu \mathrm{l}$ of deionized water was used as a blank. Then 120 
$\mu 1$ of Bradford reagent and $80 \mu 1$ of deionized water were added to each well. The plate was then placed on a shaker for $30 \mathrm{~min}$ at room temperature to ensure that sample and reagent were well mixed. Then absorbance at $595 \mathrm{~nm}$ was measured using an ELX 808 Automated Microplate Reader (Bio-Tek Instruments, INC, Winoosk, Vermont, USA). The samples were assayed in duplicate or triplicate. This protocol was applied to protein solutions with concentration between 50 to $500 \mathrm{mg} / \mathrm{mL}$. Bovine serum albumin was used to prepare a standard curve and measured by the same protocol.

\section{Lutein extraction from purified TTR}

The 2-mL TTR solution was mixed with $2 \mathrm{~mL}$ of ethanol $(0.01 \% \mathrm{BHT})$ in a glass tube to precipitate proteins. The mixture was vortexed for $30 \mathrm{sec}$ followed by the addition of $4 \mathrm{~mL}$ of chloroform $(0.01 \% \mathrm{BHT})$. The mixture was partitioned in a separation funnel and the chloroform layer was saved. This partition step was repeated 4 times and the chloroform fractions were combined and dried under vacuum. 4.8 nmol unlabeled lutein in ethanol $(0.01 \% \mathrm{BHT})$ was then added as a carrier to provide adequate mass for GCC-IRMS analysis. The combined chloroform extract and spiked unlabeled lutein standard were then dried under vacuum again. The dried sample was redissolved in $50 \mu 1$ of ethyl ether $+150 \mu l$ mobile phase $\mathrm{A}$ (methanol $+0.1 \%$ ammonium acetate), and $198 \mu \mathrm{l}$ was injected into the HPLC.

\section{Lutein derivatization}

The HPLC system used in the isolation of the lutein from the TTR extract was comprised of the following equipment (Waters, Milford, MA, USA): a 717Plus Autosampler with temperature control set to $5^{\circ} \mathrm{C}$, two 510 solvent delivery systems, and a 996 photodiode array detector. The system was operated with Millennium 32 Chromatography Manager Software. The lutein fraction was collected from a $5-\mu \mathrm{m} \mathrm{C} 30250 \times 4.6 \mathrm{~mm}$ analytical 
column (Carotenoid Column, YMC, Wilmington, NC, USA). Carotenoids were eluted by a linear gradient [100:0 methanol (0.1\% ammonium acetate) to $0: 100$ methyl-tert butyl ether (MTBE) over $30 \mathrm{~min}(1 \mathrm{ml} / \mathrm{min})]$. Solvents were HPLC grade and the mobile phase was filtered (Whatman Nylon Membrane Filter, $0.2 \mu \mathrm{m}$, Whatman International Ltd, Maidstone, England). Elution of carotenoids was monitored at $453 \mathrm{~nm}$. The lutein faction was collected, dried under vacuum, and redissolved in $50 \mu 1$ of ethyl ether $+150 \mu 1$ of methanol $(1 \mathrm{~g} / \mathrm{L}$ ammonium acetate) and repurified by injecting $195 \mu \mathrm{l}$ into the HPLC system, using the same reversed-phase HPLC conditions. The lutein peak identities were confirmed by comparison of photodiode-array spectra with that of a commercial lutein standard extracted from marigold flower (Kemin Foods, Des Moines, IA, USA). Purified lutein was dissolved in cyclohexane and hydrogenated to prevent thermal degradation during $\mathrm{GC}$ separation prior to IRMS analysis. The hydrogenation tubes were filled with argon. $10 \mathrm{mg}$ of $5 \%$ palladiumon-carbon (Alfa Aesar, Ward Hill, MA, USA) catalyst was added to the tubes promptly, followed by $0.5 \mathrm{~mL}$ of HPLC-grade cyclohexane and $0.5 \mathrm{~mL}$ of glacial acetic acid containing $0.02 \mathrm{M} \rho$-toluenesulfonic acid monohydrate (Aldrich, Milwaukee, WI, USA) and maintained under positive hydrogen gas pressure for $30 \mathrm{~min}$. The purified lutein fraction that was suspended in $250 \mu 1$ of cyclohexane was then added. The reaction mixture was maintained under positive hydrogen pressure $(12 \mathrm{psi})$ overnight with stirring at $60^{\circ} \mathrm{C}$. The mixture was washed twice with $2 \mathrm{~mL}$ of HPLC-grade water to remove acid and catalyst. The products were dried under vacuum and stored under argon at $-20^{\circ} \mathrm{C}$ until analyzed by GCC-IRMS.

\section{GCC-IRMS analysis}

A 5890A Hewlett-Packard (Wilmington, DE, USA) gas chromatograph fitted with a Fisons/VG Isotech Isochrom Gas Chromatography-Combustion interface to the Fisons/VG 
Isotech (Micromass UK Ltd, Manchester, UK) Optima Isotope Ratio Mass Spectrometer was used to measure the stable carbon ratio of the perhydro- $\beta$-carotene derivative of lutein. A 10 $\mathrm{m} \times 0.25 \mathrm{~mm}$ I.D. $\left(0.25 \mu \mathrm{m}\right.$ thickness) $\mathrm{DB}^{\mathrm{TM}}-1$ (J\&W Scientific, Folsom, CA, USA) fused silica capillary column with on-column injector was used as carrier gas at a flow rate of 40 $\mathrm{cm} / \mathrm{sec}$. The temperature program was started from $50^{\circ} \mathrm{C}$ followed by a gradient of $30^{\circ}$ $\mathrm{C} / \mathrm{min}$ to $150^{\circ} \mathrm{C}$ followed by a gradient of $30^{\circ} \mathrm{C} / \mathrm{min}$ to $150^{\circ} \mathrm{C}$ followed by a gradient of $15^{\circ}$ $\mathrm{C} / \mathrm{min}$ to $325^{\circ} \mathrm{C}$. Then the temperature was held at $325^{\circ} \mathrm{C}$ for $20 \mathrm{~min}$. After injection into the GCC-IRMS, perhydro- $\beta$-carotene was quantitatively combusted to $\mathrm{CO}_{2}$ and $\mathrm{H}_{2} \mathrm{O}$. Water was then removed by a chemical trap and $\mathrm{CO}_{2}$ gas was purified by chromatography on a Poropak QS column (4 mm I.D. $\times 2 \mathrm{~m}$ ) at $60^{\circ} \mathrm{C}$ before entry into the dual inlet of the isotope ratio mass spectrometer. The computer-generated carbon isotope ratio measurements, expressed in delta $(\delta)$ per mil (\%o) units, were used to calculate the atom percent ${ }^{13} \mathrm{C}$ in each sample according to the following equation

$$
\text { Atom } \%{ }^{13} \mathrm{C}=\frac{\left(100 \times \mathrm{R}_{\mathrm{PDB}}\right) \times\left(\delta^{13} \mathrm{C} / 1000+1\right)}{1+\left(\mathrm{R}_{\mathrm{PDB}}\right) \times\left(\delta^{13} \mathrm{C} / 1000+1\right)}
$$

where $\mathrm{R}={ }^{13} \mathrm{C} /{ }^{12} \mathrm{C}$. The $\mathrm{R}_{\mathrm{PDB}}$ represents the ${ }^{13} \mathrm{C} /{ }^{12} \mathrm{C}$ ratio for the international standard for carbon which was obtained from the Pee Dee Belemnite formation in South Carolina with an accepted value of $\mathrm{R}_{\mathrm{PDB}}=0.0112372 \pm 0.000009$. The atom percent $(\mathrm{AP})$ value of lutein was calculated based on the mass balance equation (Brenna et al, 1994):

$$
\begin{aligned}
& F_{m}=\left(n / n_{m}\right) F+\left(n_{l} / n_{m}\right) F_{1} \\
& \text { and } \quad A P=100 \times F(\text { in } \%)
\end{aligned}
$$


$F_{m}$ is the atom fraction of the mixtures (plasma lutein plus spiked unlabeled lutein standard). $F$ is the atom fraction of unlabeled material and $F_{1}$ is $98 \%$ for ${ }^{13} \mathrm{C}$ labeled lutein as determined by serial dilution analysis of ${ }^{13} \mathrm{C}$ tracers by using GCC-IRMS. $\mathrm{N}$ is the amount of the unlabeled material. $\mathrm{N}_{\mathrm{m}}$ is the final amount of the mixture, and $\mathrm{n}_{1}$ is the amount of labeled material. $\mathrm{F}$ is determined by directly analyzing the isotope fraction of unlabeled lutein standard without hydrogenation by using a NA1500 elemental analyzer (EA) (CE Elantech, Lakewood, NJ, USA) interfaced to the Optima Isotope Ratio Mass Spectrometer (IRMS).

\section{RESULTS}

\section{Purification of ${ }^{13}$ C-lutein tracer}

The carotenoid composition of our purified ${ }^{13} \mathrm{C}$-lutein tracer is shown in Figure 1 . The purity of the ${ }^{13} \mathrm{C}$-lutein was $96.5 \%$ with $3.5 \%$ zeaxanthin based on peak area determined by HPLC. The ultraviolet/visible absorbance spectrum of our biosynthetic ${ }^{13} \mathrm{C}$-lutein tracer measured by using HPLC with photodiode array detection is shown in Figure 2 . It is identical to the spectrum of commercial lutein standard (Kemin Industries, Des Moines, IA). In Figure 3, the electron ionization $(70 \mathrm{eV})$ mass spectrum shows the fragmentation of our

${ }^{13} \mathrm{C}$-labeled lutein which has a base peak of $\mathrm{m} / \mathrm{z} 608.4$. The molecular mass of unlabeled lutein, a $\mathrm{C}_{40}$ carotenoid, is 568.4. This further confirms the identity of our ${ }^{13} \mathrm{C}$-lutein tracer in which all carbon atoms were uniformly labeled with ${ }^{13} \mathrm{C}$. The ${ }^{13} \mathrm{C}$ content of the dose was found to be $>98 \%$ using GCC-IRMS after serial dilution with unlabeled lutein. 


\section{Purification of TTR from subject's plasma}

The protocols used to purify TTR from human plasma are summarized in Table 1. These protocols are highly reproducible and give high yields of pure product comparable to those obtained with other methods. About $8 \mathrm{mg}$ of RBP-bound TTR was purified from $250 \mathrm{~mL}$ of plasma by using Method 1 and $4.7 \mathrm{mg}$ of free TTR was purified from $100 \mathrm{~mL}$ of plasma by using Method 2. Normal levels of TTR and RBP in human plasma average $200 \mathrm{mg} / \mathrm{L}$ and 40 $\mathrm{mg} / \mathrm{L}$, respectively. Therefore, $250 \mathrm{~mL}$ and $100 \mathrm{~mL}$ contain approximately $60 \mathrm{mg}$ and $20 \mathrm{mg}$ of TTR, respectively. Among this, RBP-bound TTR is about $25 \mathrm{mg}$ estimated by the 1: 1 ratio of TTR binding to RBP. Thus the total recovery of TTR purified using Method 1 is 34\%. Free TTR in $100 \mathrm{~mL}$ plasma is about $10 \mathrm{mg}$ and the total recovery of TTR purified using Method 2 is $47 \%$. These recoveries are comparable to or even higher than those obtained with published methods $(107,108)$. Figure 5 shows the SDS-PAGE analysis of the fractions isolated from the RBP-Affinity column. The samples were submitted to SDSPAGE and compared with pure TTR standard purchased from Sigma. Lanes A, B, C, D, and $\mathrm{E}$ are Coomassie-stained fractions of our TTR purified by affinity chromatography whereas lane $\mathrm{F}$ is the commercial TTR standard. The position of the TTR bands in lanes $\mathrm{A}$ to lane $\mathrm{E}$ correspond to the monomeric mass of TTR $(14 \mathrm{kDa})$.

TTR was purified to homogeneity. The identity of TTR isolated from human plasma was confirmed by immunoblot. The result is shown in Figure 6 . Our purified TTR was highly reactive with anti-TTR antibodies which further confirms the identity of our TTR isolated from our subjects' plasma. 


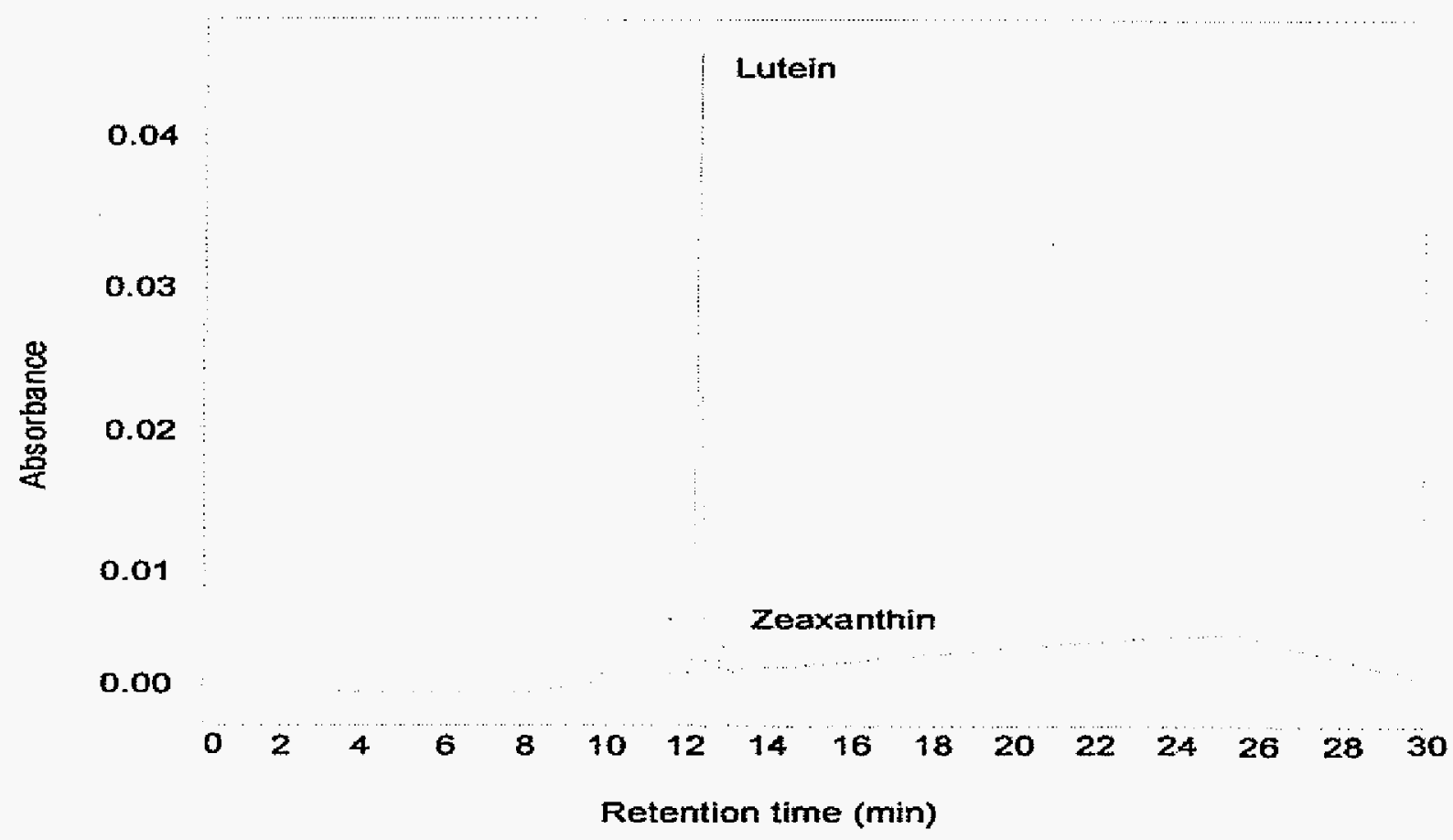

Figure 2. HPLC chromatogram showing the high purity of ${ }^{13} \mathrm{C}$ labeled lutein purified from ${ }^{13} \mathrm{C}$-labeled algae. 


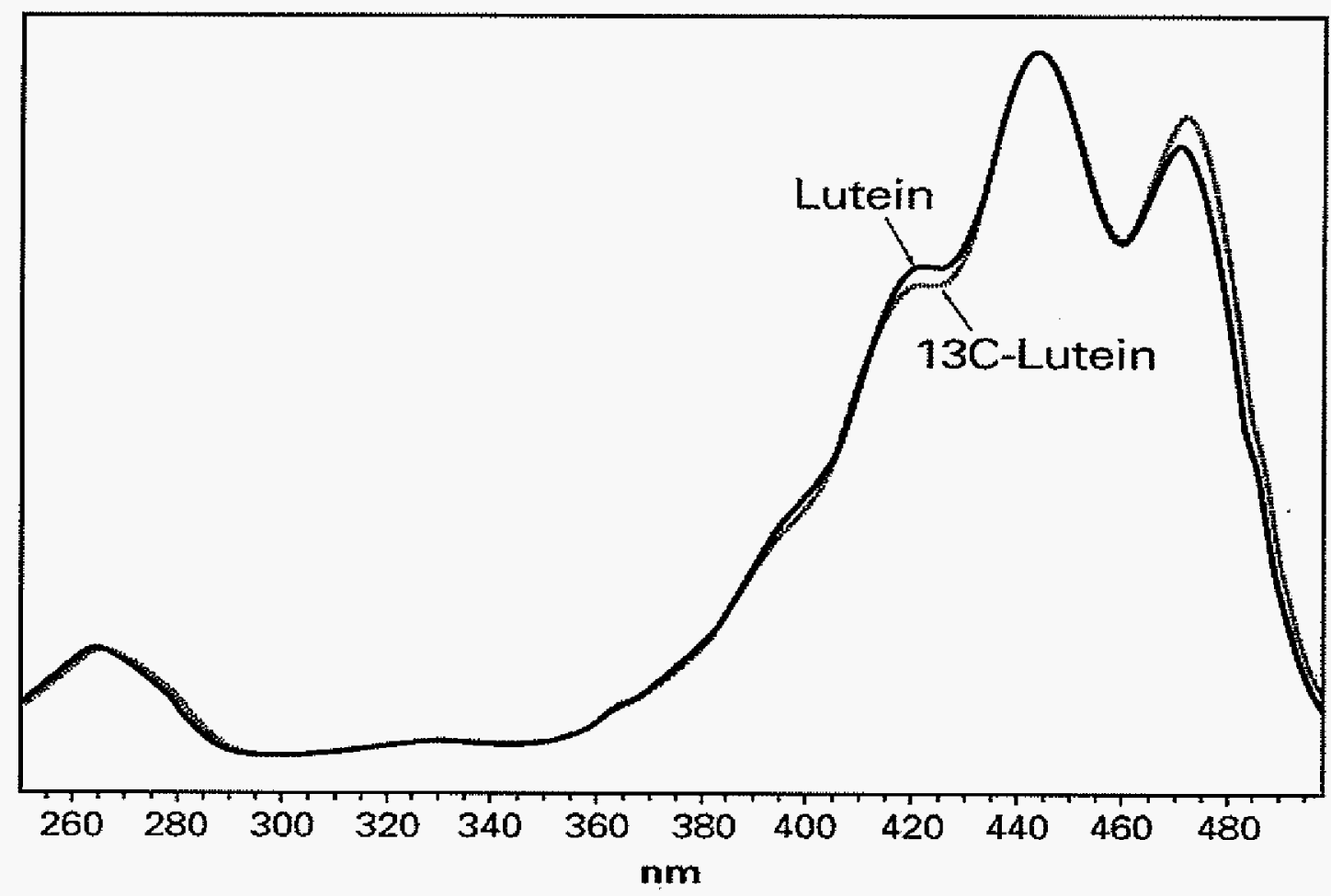

Figure 3. Near identical UV/visible absorbance spectra of commercial lutein standard and ${ }^{13} \mathrm{C}$-labeled lutein purified from ${ }^{13} \mathrm{C}$-labeled algae 


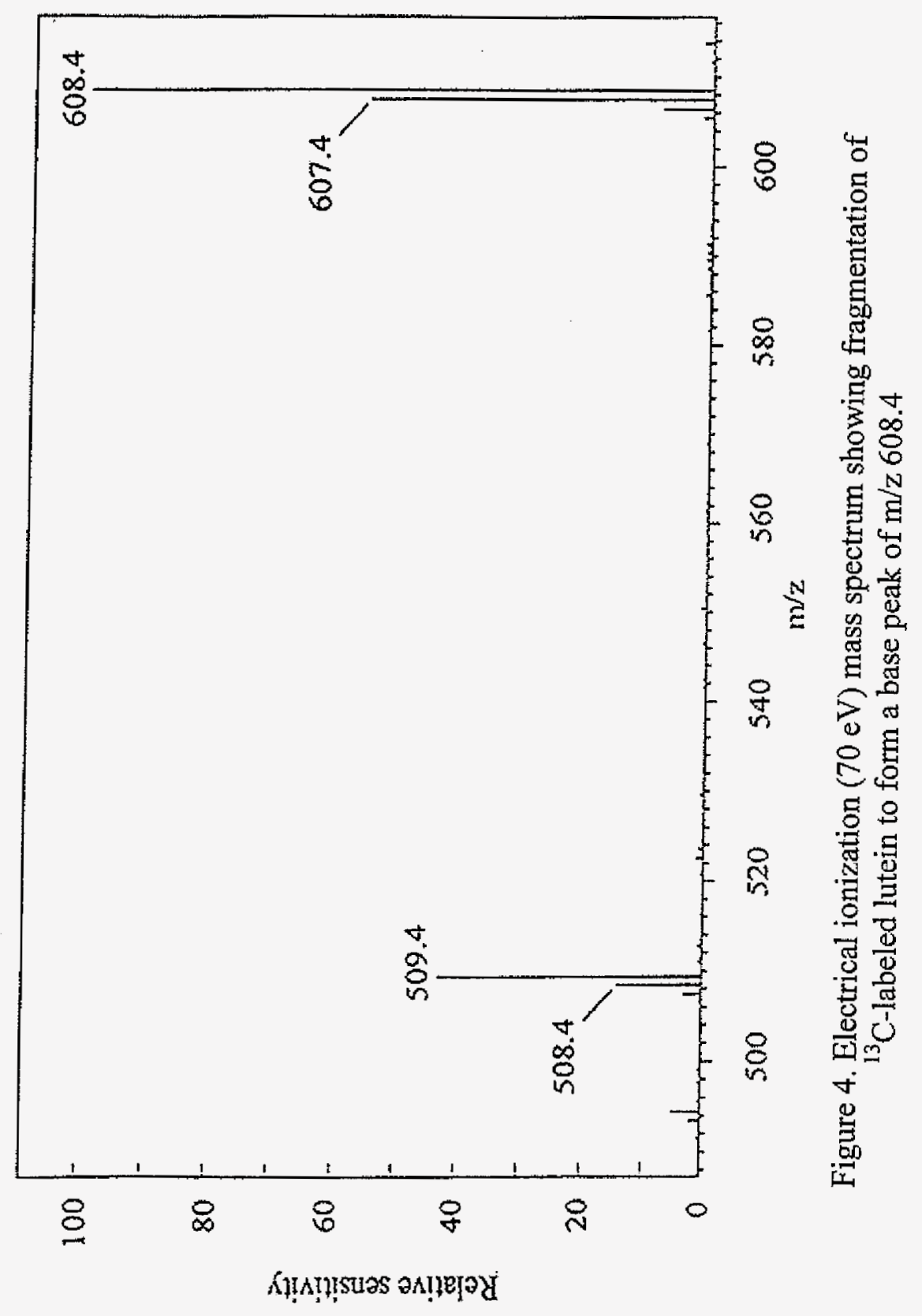


Table 1. Purification of transthyretin from human plasma.

\begin{tabular}{lll}
\hline Fraction & $\begin{array}{l}\text { Method 1 }(250 \mathrm{~mL}) \\
\text { Total protein }(\mathrm{mg})^{*}\end{array}$ & $\begin{array}{l}\text { Method 2 }(100 \mathrm{~mL}) \\
\text { Total protein }(\mathrm{mg})^{*}\end{array}$ \\
\hline $\begin{array}{l}\text { Plasma } \\
\text { DEAE column }\end{array}$ & 17050 & 7540 \\
$\begin{array}{l}\text { Ammonium sulfate } \\
\text { precipitation }\end{array}$ & 86 & 3900 \\
Phenyl-sepharose column & 39 & 21 \\
Affinity column & $8.3^{+}$ & $4.7^{+}$ \\
& & \\
\hline
\end{tabular}

* Protein amount was measured by Bradford method.

${ }^{*}$ Pure TTR

With Method 1, we did not observe visibly yellow color in the TTR fraction during the purification procedure. However, when the initial DEAE chromatography step was omitted in Method 2, each of the 3 fractions collected from the phenyl-sepharose column (TTR, RBP and unidentified $3^{\text {rd }}$ fraction) were visible yellow. Each of the concentrated fractions was analyzed by photodiode-array (PDA) spectrophotometer and SDS-PAGE (Figure 7). In addition to the protein absorbance at $280 \mathrm{~nm}$, the TTR-containing fraction (peak 1) showed absorbance from 400 to $500 \mathrm{~nm}$ with the maximum absorbance at $414 \mathrm{~nm}$ (Figure 8). Peak 2 (containing RBP) and Peak 3 also showed absorbance from $380 \mathrm{~nm}$ to $550 \mathrm{~nm}$ (Figure 8). But none of these peaks had a spectrum characteristic of a carotenoid. When the TTRcontaining peak was applied to the RBP-affinity column to obtain further purification, no yellow color was observed in the final purified TTR faction. The PDA spectrophotometric 
data supported this observation. There was no absorbance between 400 and $500 \mathrm{~nm}$ in the final purified TTR fraction (Figure 9).

$\begin{array}{llllll}\text { A } & \text { B } & \text { C } & \text { D } & \text { E } & \text { F }\end{array}$

$\begin{array}{rr}150 \mathrm{kDa} & - \\ 100 \mathrm{kDa} & - \\ 75 \mathrm{kDa} & - \\ 50 \mathrm{kDa} & - \\ 35 \mathrm{kDa} & - \\ 25 \mathrm{kDa} & -\end{array}$

$15 \mathrm{kDa}$

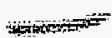

Figure 5. SDS-PAGE of human TTR isolated with affinity chromatography: (A-E) purified TTR, (F) commercial TTR standard. 
A B $\quad$ C $\quad$ D

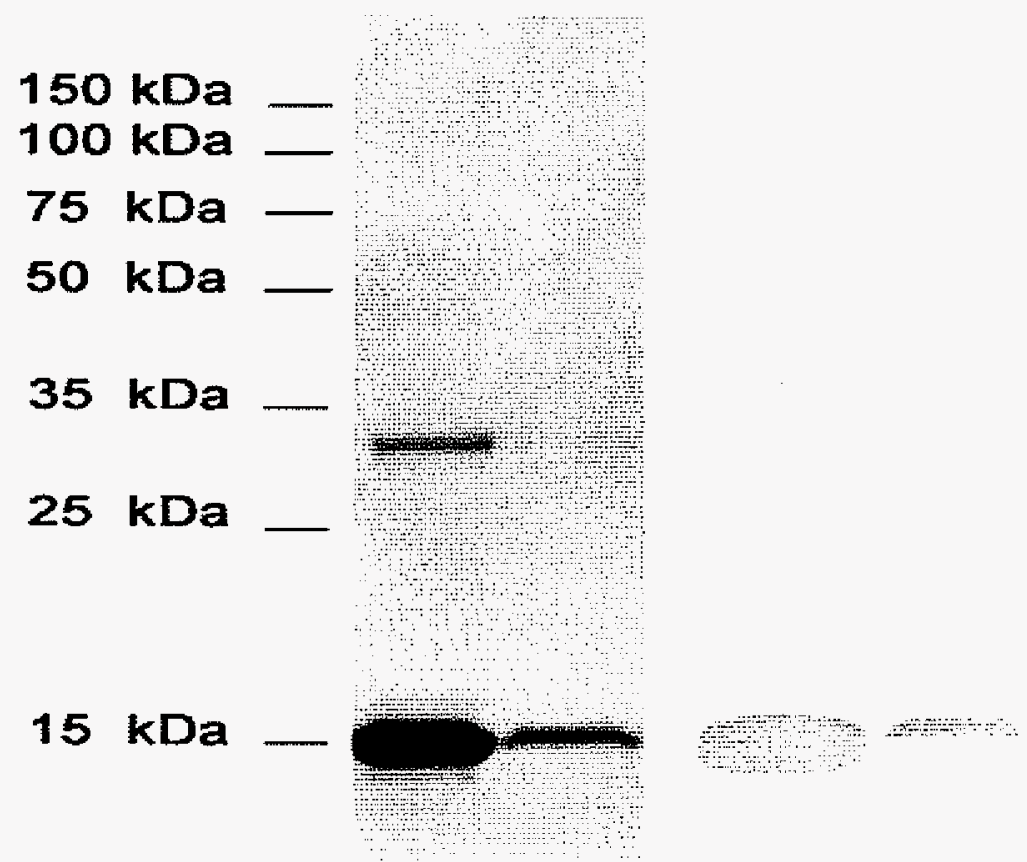

Figure 6. SDS-PAGE gel (left) and immunoblot (right) of human TTR: commercial TTR standard (A and C), purified TTR from human plasma (B and D). 


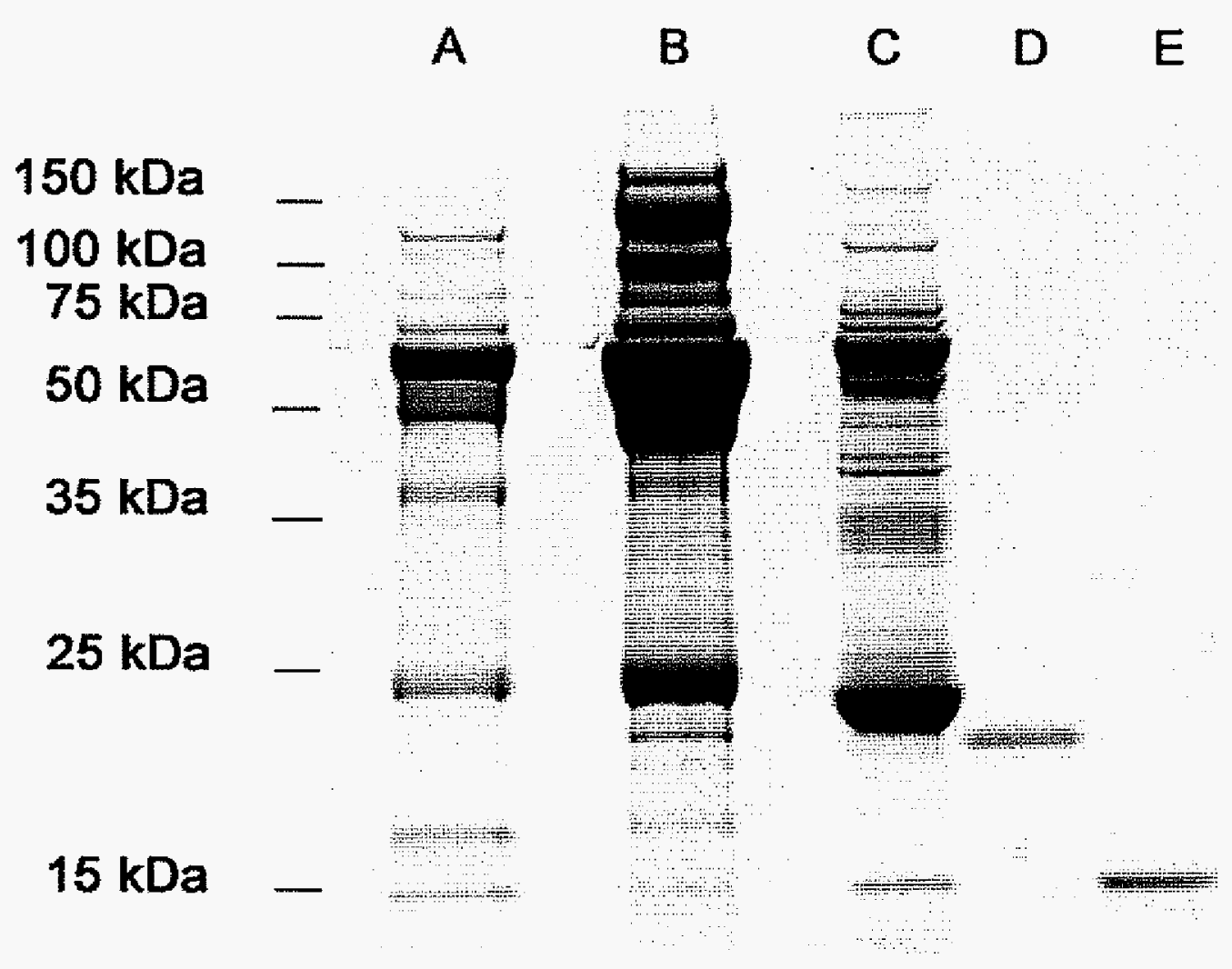

Figure 7. SDS-PAGE of material isolated with phenyl-sepharose column: Coomassiestained peak 1 (A), peak 2 (B), peak 3 (C), commercial human RBP standard (D), and commercial human TTR standard (E). 

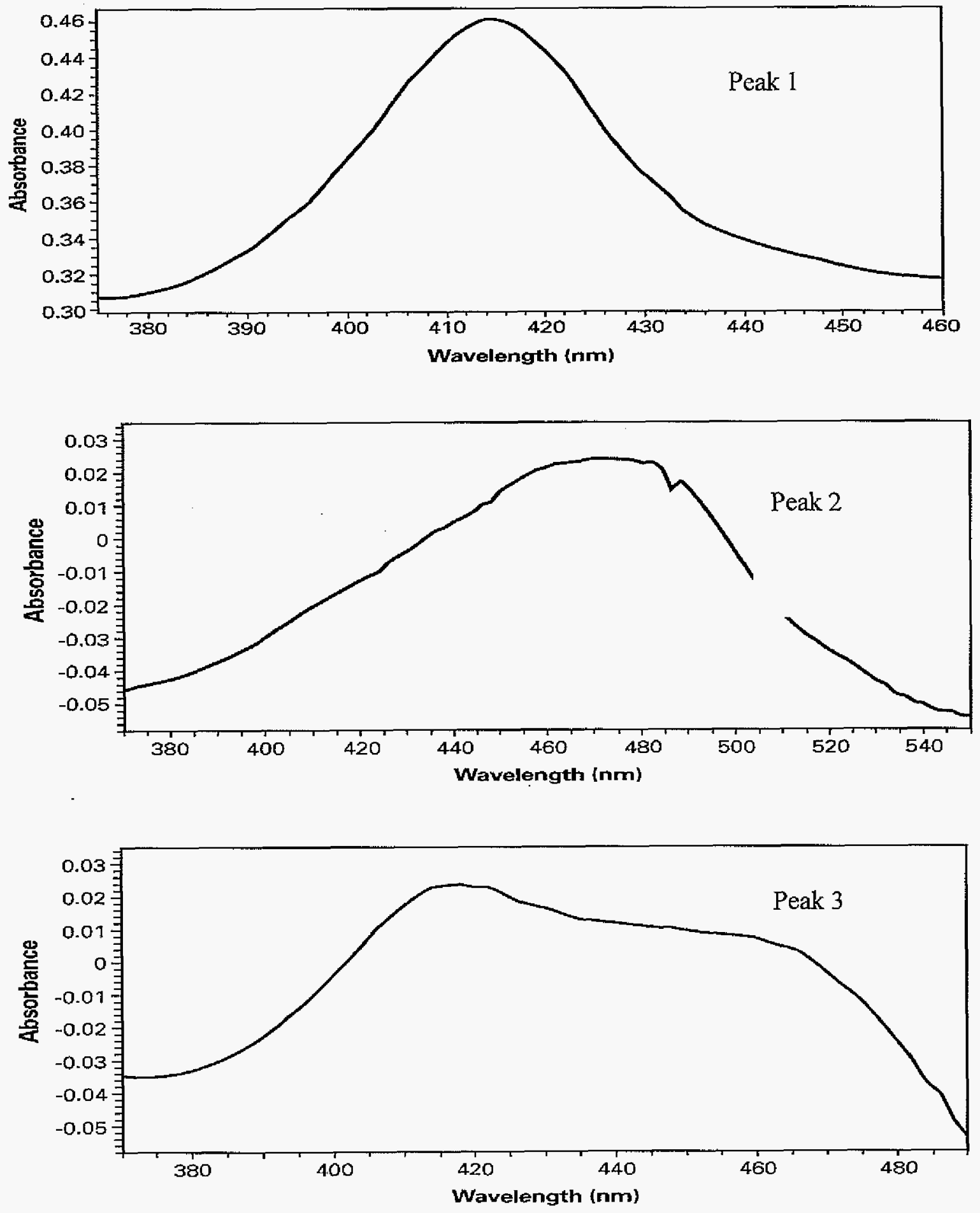

Figure 8. Absorbance spectra of fractions isolated with phenyl-sepharose column by using Method 2. 


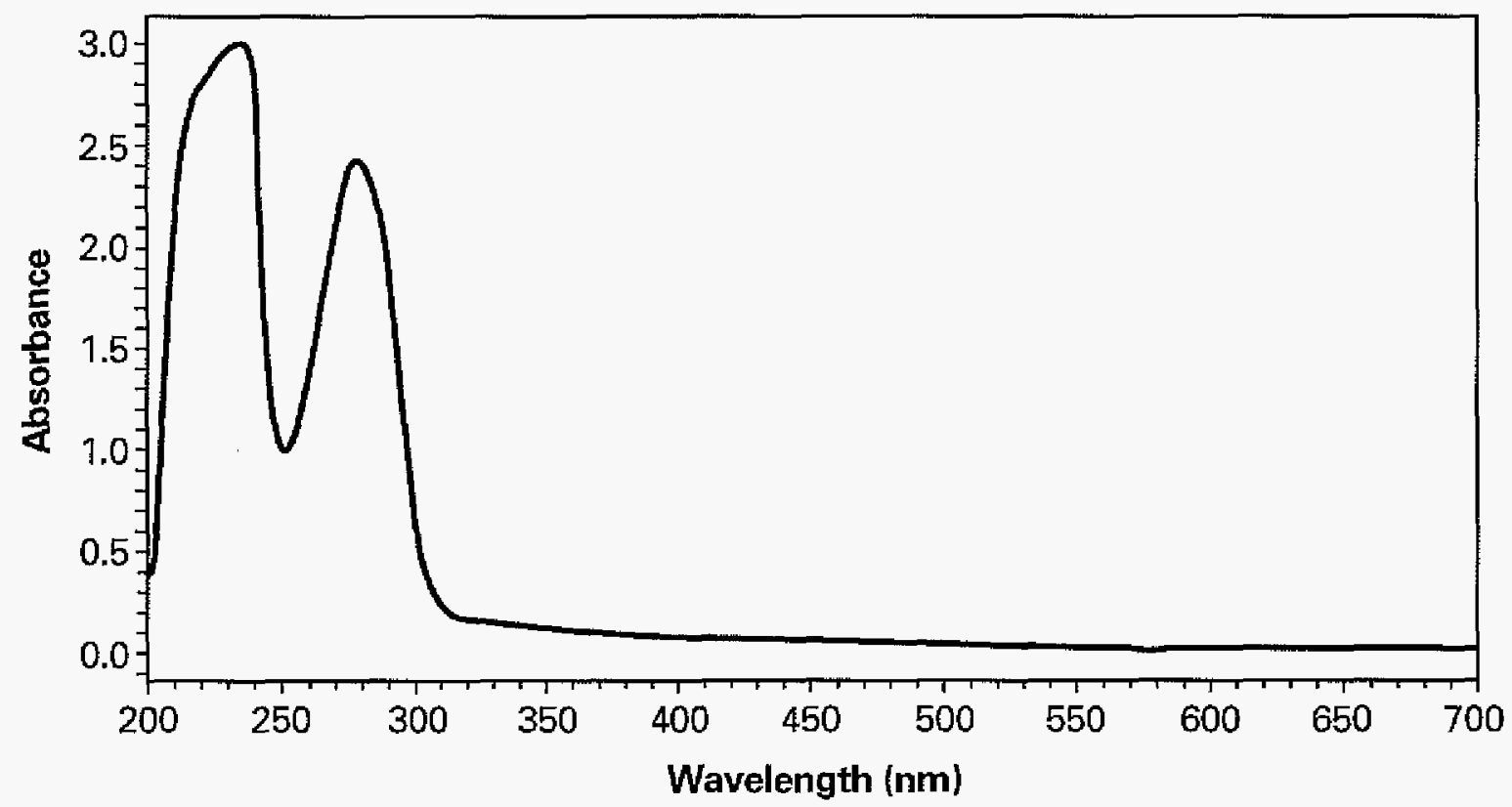

Figure 9. UV/visible absorbance spectrum of TTR purified to homogeneity by using RBP-affinity chromatography

\section{Extraction of the associated component from the human TTR}

The TTR was precipitated with ethanol and extracted with chloroform (0.01\% BHT). 4.8 nM of unlabeled lutein was added to obtain a visible peak during HPLC isolation and sufficient mass to enable GCC-IRMS analysis. The HPLC chromatogram is shown in Figure 10. The major peak which eluted at $12.253 \mathrm{~min}$ is a mixture of ${ }^{13} \mathrm{C}$-lutein and unlabled lutein. The unlabeled lutein was also analyzed by HPLC using the same procedure. The HPLC chromatograms of both unlabeled lutein and extract of the subjects' sample spiked with unlabeled lutein are similar with regard to the carotenoid profile. 


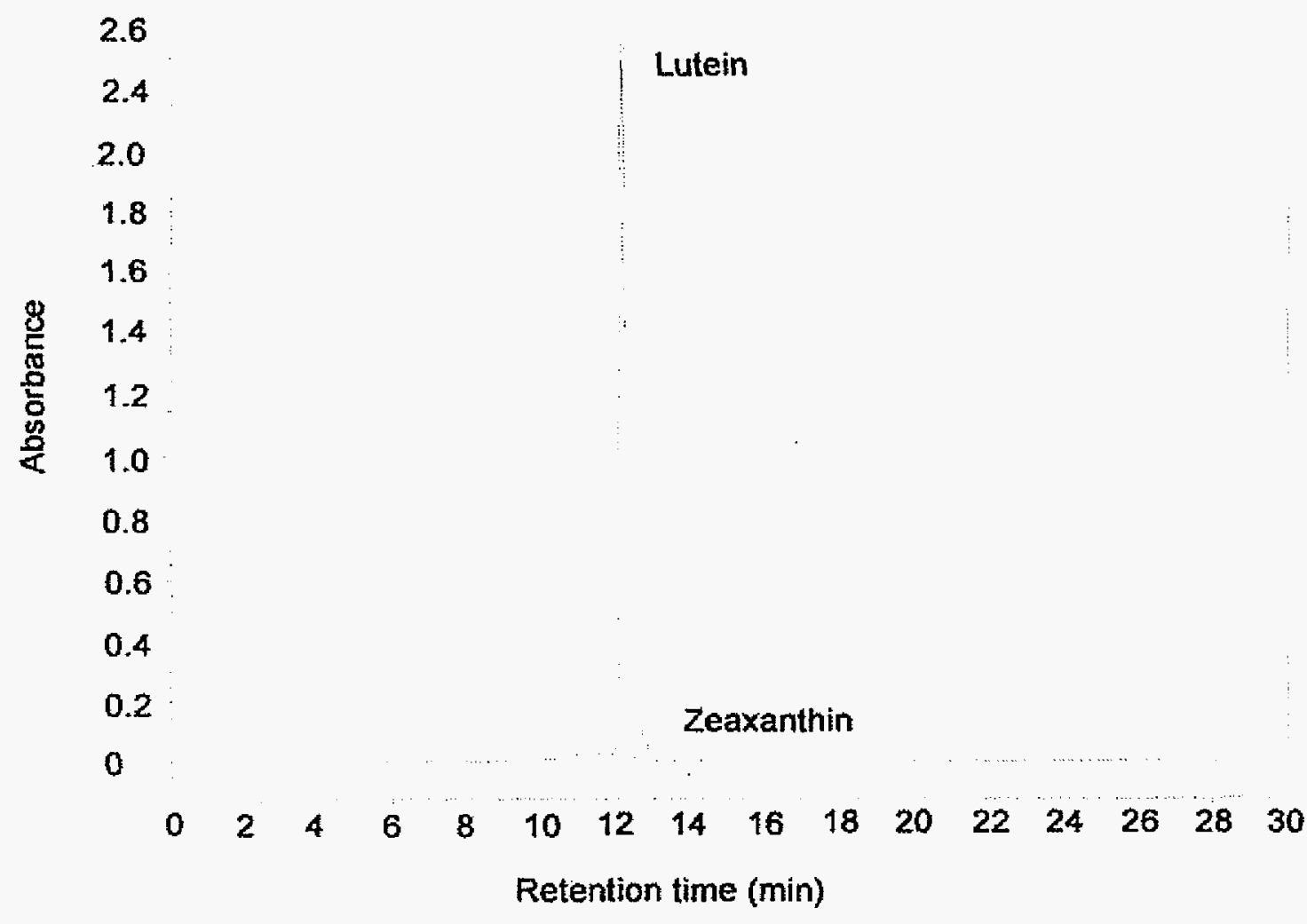

Figure 10. HPLC chromatogram showing the isolation of lutein from the TTR extract spiked with unlabeled lutein. 


\section{Derivatization of lutein}

Because lutein is thermally labile, it must be converted to a heat stable form for GCCIRMS analysis. Catalytic hydrogenation of lutein produces the major product perhydro $\beta$ carotene and secondary products (95). The identity of the major product was confirmed by GC-MS. The electron ionization $(70 \mathrm{eV})$ mass spectrum shows the fragmentation of perhydro- $\beta$-carotene with mass at $\mathrm{m} / \mathrm{z} 558.7$ (Figure 10). The incomplete yield of perhydro$\beta$-carotene produced from lutein derivatization suggested a potential for isotopic fractionation during the hydrogenation of plasma lutein for GCC-IRMS analysis. The stable carbon isotope ratio (expressed as $\delta^{13} \mathrm{C}$ vs. the international standard, $\mathrm{PDB}$, in permil units, denoted as \%o) of lutein measured without derivatization by elemental analyzes (EA-IRMS) was $-30.82 \pm 0.10 \%$ (mean $\pm \mathrm{SD} ; \mathrm{n}=4)$; the stable carbon isotope ratio of perhydro- $\beta$-carotene product of lutein hydrogenation measured by using GCC-IRMS was $-30.97 \pm 0.27 \%$ (mean $\pm \mathrm{SD} ; \mathrm{n}=7$ ). Thus our protocol for derivatization of lutein did not result in carbon isotopic fractionation which would preclude accurate determination of ${ }^{13} \mathrm{C}$ enrichment in lutein isolated from human TTR.

\section{GCC-IRMS analysis}

A representative GCC-IRMS plot of hydrogenationed lutein is shown in Figure 11. A well-defined perhydro- $\beta$-carotene peak indicated a highly-purified sample and enables high precision measurement of the ${ }^{13} \mathrm{C} /{ }^{12} \mathrm{C}$ ratio. In our study, the carbon atoms of the perhydro$\beta$-carotene derivative of lutein are combusted to $\mathrm{CO}_{2}$, which is admitted to the mass spectrometer. Ion currents at $\mathrm{m} / \mathrm{z} 44\left({ }^{12} \mathrm{CO}_{2}\right), 45\left({ }^{13} \mathrm{CO}_{2}+{ }^{12} \mathrm{C}^{17} \mathrm{O}^{16} \mathrm{O}\right)$, and $46\left({ }^{12} \mathrm{C}^{18} \mathrm{O}^{16} \mathrm{O}\right)$ are continuously monitored using three Faraday cup detectors. To control for instrumental 


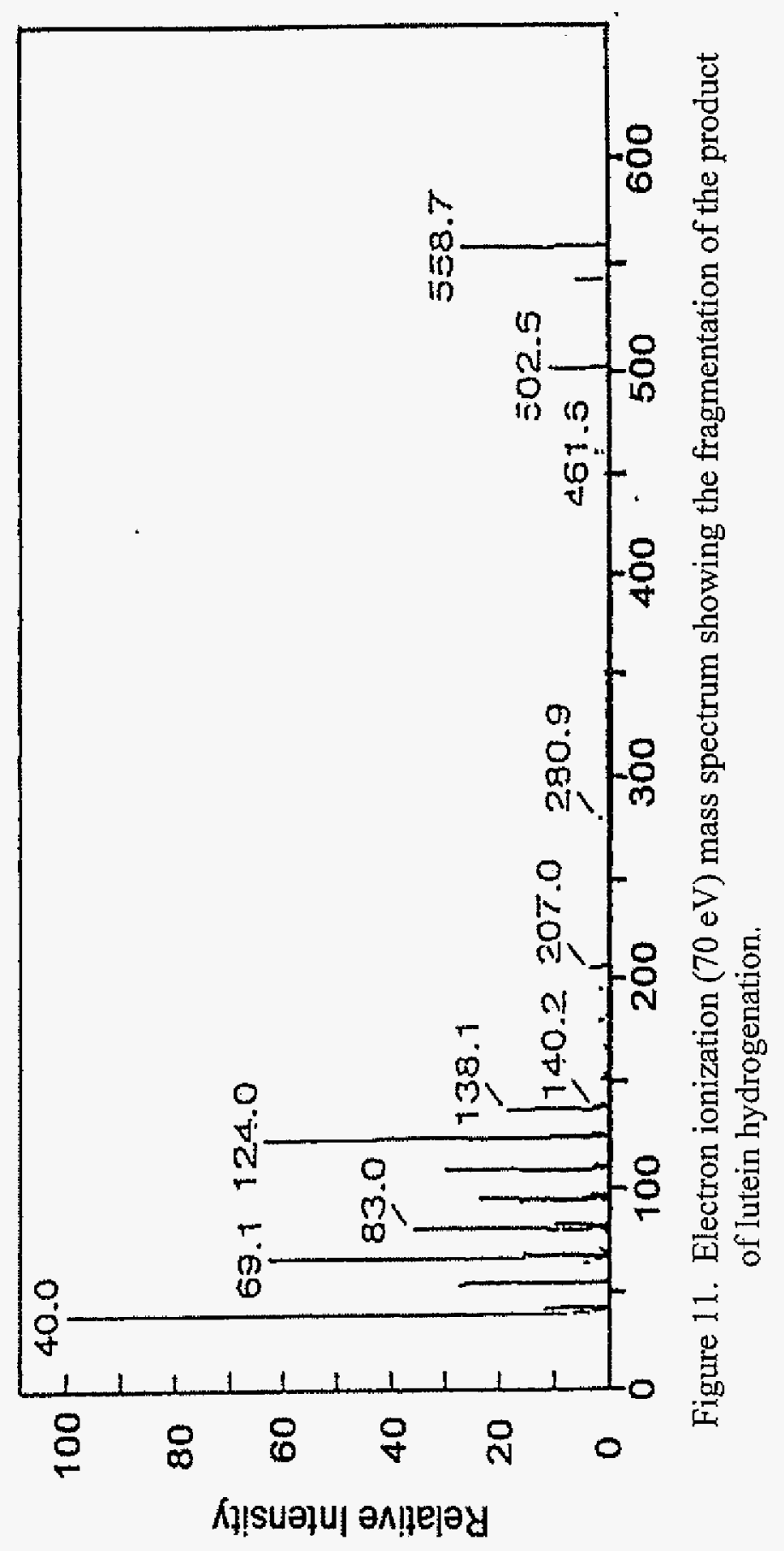



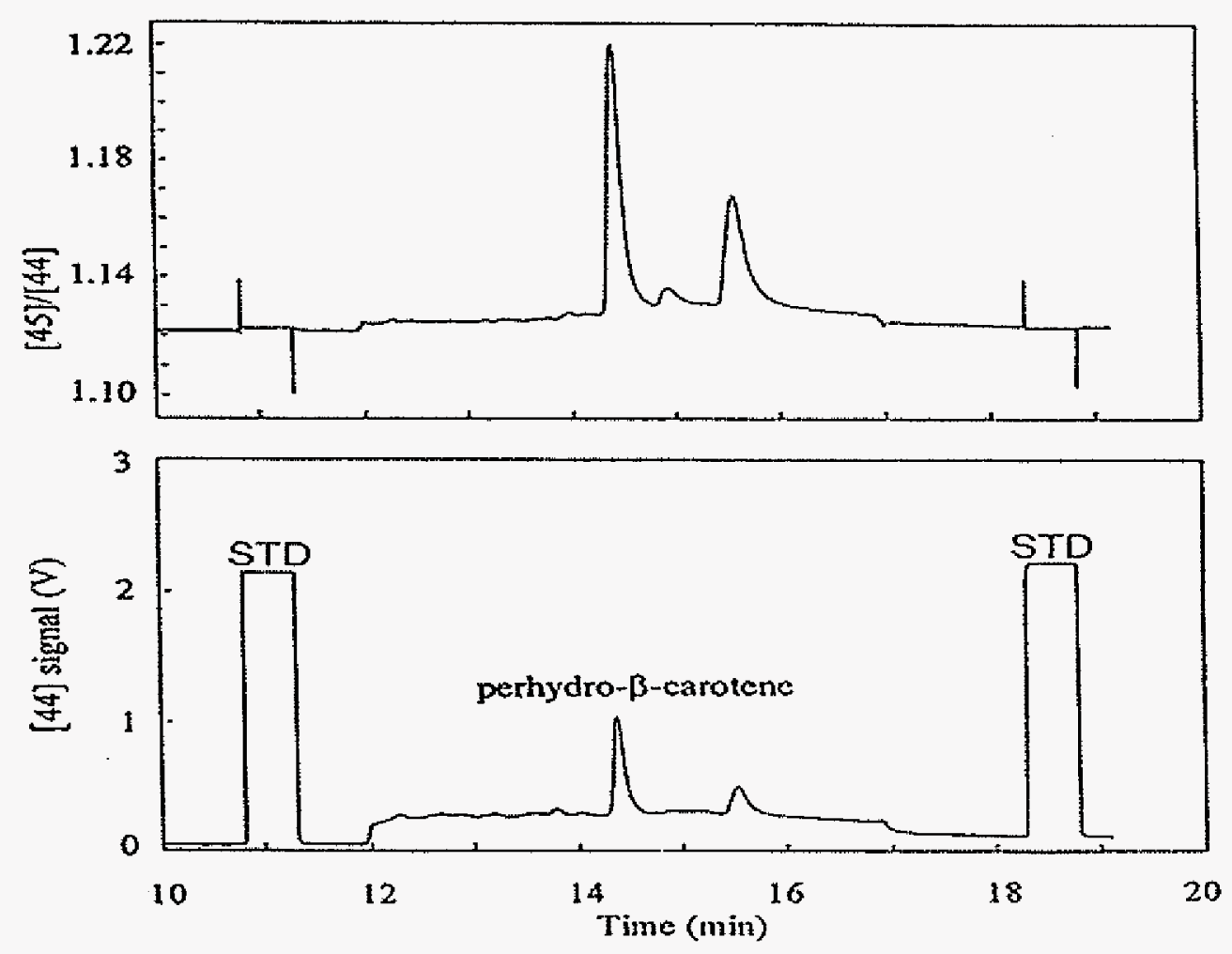

Figure 12. GCC-IRMS plot of derivatization product of lutein.

effects, the isotope ratio of $\mathrm{CO}_{2}$ derived from the analyte is compared with that from a $\mathrm{CO}_{2}$ standard, Pee Dee Belemnite (PDB). Results are expressed in $\delta$ notation defined as

$$
\delta(\%)=\left(\frac{\mathbf{R}_{\text {sample }}-\mathbf{R}_{\text {stundard }}}{\mathbf{R}_{\text {standard }}}\right) \times 10^{3}
$$

where $\mathrm{R}$ is the ${ }^{13} \mathrm{C} /{ }^{12} \mathrm{C}$ ratio. The computer-generated $\delta$ value is used to calculate the atom percent ${ }^{13} \mathrm{C}$ in the analyte, as previously described. The carbon isotope ratios $\left({ }^{13} \mathrm{C}\right)$ of lutein from 3 subjects' TTR extracts by using Method 1were $-30.57,-29.17$, and -27.33 , respectively. The $\delta{ }^{13} \mathrm{C}$ for the subject whose TTR was purified by using Method 2 was -35.04. These values were not signification difference from the $\delta^{13} \mathrm{C}$ of $-30.82 \%$ 
determined from the unlabeled lutein standard, which indicated that there was no ${ }^{13} \mathrm{C}$ enrichment in the TTR extract.

\section{DISCUSSION}

In this study, we successfully purified and crystallized ${ }^{13} \mathrm{C}$-labeled lutein from crude lipid extract of ${ }^{13} \mathrm{C}$-labeled algae. The purity of our ${ }^{13} \mathrm{C}$-labeled lutein tracer was $96.5 \%$ with $3.5 \%$ zeaxanthin and no $\beta$-carotene. Human subjects were dosed with purified ${ }^{13} \mathrm{C}$-labeled lutein for 3 days and $500 \mathrm{~mL}$ of blood of each subject were collected for the TTR isolation. Also, in this study, both TTR and RBP were purified in homogeneity from human plasma. A large amount of TTR and RBP were purified from liters of outdated human plasma and used as ligands for the affinity columns. TTR-sepharose affinity column and RBP-sepharose affinity columns were packed in our lab. The affinity columns were used repeatedly during a period of 10 months without sign of degradation or loss of binding capacity. With Method 1, 7.6 $\mathrm{mg}, 8.0 \mathrm{mg}$, and $8.3 \mathrm{mg}$ of RBP-bound TTR were purified from 3 subjects' plasma (250 mL), respectively. With Method 2, $4.7 \mathrm{mg}$ of free TTR was obtained from 1 subject's plasma (100 $\mathrm{mL}$ ).

\section{Purification of the tracer}

Purified ${ }^{13} \mathrm{C}$-labeled lutein is not commercially available. Green algae are a good source of biosynthetic carotenoids. Green algae grown in a closed-system using ${ }^{13} \mathrm{CO}_{2}$ as the sole carbon source were used in our previous studies to economically produce ${ }^{13} \mathrm{C}$-labeled lutein for use as a stable tracer (95). In this study, acetone was used initially to extract carotenoids from the crude lipid extract of the algae. Hexane, which is a good solvent for carotenoids with low toxicity and high volatility, was then used to extract carotenoids and exclude other 
fat soluble materials. A modified solvent partitioning procedure based on a protocol established in our lab (95) was used to purify lutein. Since lutein has two hydroxyl groups, it is easily partitioned into the methanol phase whereas $\beta$-carotene remains in the hexane phase. With methanol/hexane partitioning, $\beta$-carotene and lutein can be separated and then further purified by crystallization. Ethyl ether was used after the methanol partitioning because it has high volatility and is easy to evaporate to obtain dry products. Hexane is a good solvent for $\beta$-carotene but not for lutein. The solubility of $\beta$-carotene and lutein in hexane are 600 $\mathrm{mg} / \mathrm{L}$ and $20 \mathrm{mg} / \mathrm{L}$, respectively. Hence it is used during the wash step for additional removal of $\beta$-carotene contamination from the lutein products. At least $1 \mathrm{mg}$ of carotenoid is necessary for crystallization. Crystallization of lutein can be achieved by dissolving purified dried lutein in warm $\left(40^{\circ} \mathrm{C}\right)$ methanol and then storing it at $-20^{\circ} \mathrm{C}$ overnight. Using this protocol, high purity $\left(>96 \%\right.$ ) of ${ }^{13} \mathrm{C}$-labeled lutein tracer can be obtained with minute contamination by zeaxanthin $(\sim 3 \%)$ and no $\beta$-carotene.

\section{TTR purification}

TTR occurs in human plasma as a tetramer composed of apparently identical subunits each of $14 \mathrm{kDa}$ molecular weight. Each subunit contains one polypeptide chain with a single cysteinyl residue at position 10 (98). RBP forms a stable protein-protein complex with TTR in human circulation, with an association constant of the order of $10^{6}$ to $10^{7}(99)$. The interaction of RBP with TTR is very sensitive both to ionic strength and to $\mathrm{pH}(100,101)$. RBP and TTR do not form a complex at an ionic strength of $2 \mathrm{mM}$ or lower, and RBP-TTR affinity decreases rapidly above $\mathrm{pH} 9$ and below pH 5 (101).

Isolation of TTR and RBP are notably difficult, laborious, and time consuming. A number of procedures for the purification of human TTR and RBP have been reported (102). 
Most of the reported purification schemes are similar in that they employ combinations of ion-exchange chromatography and gel filtration or affinity chromatography to achieve human TTR and RBP purification. In these schemes, TTR and RBP have been isolated from serum or plasma by first isolating the RBP-TTR complex and then dissociating the complex into two components. Then more specific chromatography was carried out to obtain the more purified form of each protein. Berni et al. (103) reported a new purification method. In their procedure, a phenyl-sepharose CL-4B column was employed. This hydrophobic interaction chromatography coupled to the ammonium sulfate precipitation is used to dissociate the RBP-TTR complex and eliminates the bulk of other plasma proteins. The dissociation of RBP-TTR complex may result from the existence of hydrophobic regions in the contact areas between the two proteins that compete for the hydrophobic binding sites on the matrix. As an alternative explanation, the complex may bind to the matrix with relatively high affinity and release RBP at the end of the gradient, when the ionic strength of the eluant is 0.05 and, therefore, possibly favorable for the dissociation of the complex. Use of affinity chromatography in purification of TTR or RBP has been reported by several researchers $(104,105)$. This procedure is highly reproducible and gives good recoveries of highly purified material. In addition, once packed, the affinity column is extremely stable and can be used repeatedly over a period of 8 months for more than 50 chromatographies without degradation or any signs of decrease in capacity (104).

In our study, we used a purification procedure provided by Dr. David Ong, Vanderbilt University, which consisted of ion-exchange chromatography (DEAE column), hydrophobic interaction chromatography (phenyl-sephaose column), and affinity chromatography. Large amounts of pure TTR and RBP for preparing affinity columns are not commercially available 
so we needed to isolate pure TTR and RBP from human plasma. We used outdated human plasma provided by a local blood bank as our source of human TTR and RBP. After pure TTR was obtained by several isolation chromatographies (ion-exchange chromatography, hydrophobic interaction chromatography, and a $2^{\text {nd }}$ ion-exchange chromatography), a TTRsepharose column was packed and used to purify RBP. When the desired amount of pure RBP was obtained, a RBP-sepharose column was packed. These two affinity columns were tested for their performance before use in isolation of TTR from our subjects' samples. The SDS-PAGE and immunoblot showed only a single band in both pure TTR and RBP fractions. The RBP-affinity column was employed in the purification of our subjects' TTR. To purify TTR from our subject's samples, two methods were used. The first is comprised of ion-exchange chromatography (DEAE column), hydrophobic interaction chromatography (phenyl-sepharose column), and affinity chromatography (RBP-sepharose column). With this method, only RBP-bound TTR was isolated from human plasma. The final product (pure human TTR) purified by the RBP-affinity column did not have visible color or absorbance in the range from 400 to $550 \mathrm{~nm}$ as analyzed using a PDA spectrophotometer.

In Method 2, with a smaller initial volume $(100 \mathrm{~mL})$ of plasma, we used ammonium sulfate precipitation combined with phenyl-sepharose column as the first step. This protocol allowed us to isolate both RBP-bound TTR as well as free TTR. A total of 3 peaks were eluted and analyzed with the PDA spectrophotometer. Each peak had yellow color but of different intensities. The SDS-PAGE analysis showed that peak 1 contained TTR while peak 2 contained RBP. The PDA spectrophotometric data indicated that components with absorbance in the range of $400 \mathrm{~nm}$ to $550 \mathrm{~nm}$ were present in all 3 peaks. However, the spectra of these 3 peaks did not show the typical spectra characteristics of carotenoids which 
have three strong absorbance maxima in the region 400 to $500 \mathrm{~nm}$ (Figure 7). Protein sequence data suggested that the major protein which occurred in all 3 peaks is lipoprotein $\mathrm{A}$ which is a major protein present in HDL. The yellow color disappeared after peak 1 was further purified by affinity chromatography. In the final pure TTR product, no yellow color or absorbance between 400 and $550 \mathrm{~nm}$ were detected.

\section{Derivatization of lutein}

The conjugated polyene system of carotenoids is thermally unstable. Therefore, lutein must be converted to derivatives that are thermally stable and volatile at approximately $300^{\circ} \mathrm{C}$ prior to GCC-IRMS analysis (94). Catalytic hydrogenation of lutein produces a major product perhydro- $\beta$-carotene ( $\mathrm{m} / \mathrm{z} 558.6)$ and secondary products. Our protocol for hydrogenation for lutein was optimized by increasing the yield of perhydro- $\beta$-carotene. Several catalysts were evaluated in our laboratory for their activities and efficiency in the reaction of alcohol hydrogenolysis and hydrogenation of lutein to yield perhydro- $\beta$-carotene. Palladium was found to be the best catalyst for lutein (95).

Solvents are also critical in the carotenoid hydrogenation reaction. They serve to increase the ease of handling, to moderate exothermic reactions, to increase rate and selectivity, and to permit hydrogenation of solid material (107). In the case of lutein, solvents that contain peroxide should be avoided to prevent possible degradation of the carotenoids (108). Our experience indicated that cyclohexane and acetic acid were the best solvent for the hydrogenolysis and hydrogenation of lutein (95).

Since the amount of lutein associated with TTR is expected to be very small, it is important to ensure sufficient and reliable yield of the perhydro- $\beta$-carotene from the lutein derivatization. Our data indicated that the protocol we used can achieve excellent yield of 
perhydro- $\beta$-carotene during the hydrogenolysis and hydrogenation of lutein, which enabled reliable GCC-IRMS analysis of nanomolar quantities of lutein. Our data also showed that our protocol for the lutein derivatization does not result in carbon isotope fractionation, and therefore the perhydro- $\beta$-carotene product is well-suited for GCC-IRMS.

\section{GCC-IRMS analysis}

Recently, GCC-IRMS was applied to investigate carotenoid metabolism in humans. The high precision of GCC-IRMS coupled with use of a per-labeled tracer enables use of a physiological amount of tracer dose and distinguishes the administered carotenoid from endogenous carotenoid. Previously, we used the high precision of GCC-IRMS to detect differences of natural abundance of ${ }^{13} \mathrm{C}$ in lutein isolated from $\mathrm{C}_{3}$ and $\mathrm{C}_{4}$ plant sources (94).

Based on our current GCC-IRMS data, no ${ }^{13} \mathrm{C}$-labeled lutein was detected in an extract of purified human TTR. In chickens, the extent of saturation of TTR with lutein was estimated to be about $50 \%$ and the binding stoichiometry was assumed to be a 1:1 molar ratio (68). We calculate that even if only a 1:100 molar ratio of lutein to TTR existed, the GCC-IRMS would detect enrichment of ${ }^{13} \mathrm{C}$-lutein in our TTR extracts. The absence of ${ }^{13} \mathrm{C}$-lutein in the extract of TTR obtained using our two isolation methods suggests that lutein is not associated with TTR in human blood, at least within the detection limits of current technology. Purified chicken TTR is a tetramer (molecular weight of $56 \mathrm{kDa}$ ) of four identical subunits (each with a molecular weight of approximately $13 \mathrm{kDa}$ ) and its thus similar to human TTR (108). However, chicken TTR is immunologically (108) and electostatically (109) different from those of human and rat. The protein sequence and structure study revealed 31 chicken to human residue differences. Compared with human TTR chicken TTR shows quite large differences in the region know to be involved in binding to retinol-binding protein; it has a 
much shorter helical component than the human protein and some of the monomer-monomer interactions are different (110). It is also reported that the N-termini of the TTR subunits are longer and more hydrophobic in chicken than in mammalian TTR (111). Systematic changes of protein structure during evolution lead to changes in function. Although the concentrations of TTR are similar in chicken and human (68), there are functional differences between chicken and human TTR. RBP and TTR form a 1:1 complex in human plasma (73) and 2:1 in chicken plasma (112). In humans, carotenoids are transported mainly by lipoproteins, which are less abundant in chicken plasma (113). In addition, human thyroxine is transported bound to TTR (40\%), thyroxine-binding globulin, TBG (50\%), and albumin (10\%). Chicken plasma does not contain TBG. About $80 \%$ of chicken thyroxine binds to albumin and less than $20 \%$ to TTR (114). Hence thyroxine binding to TTR is significantly lower in chicken than in human plasma. These differences further suggest that it is likely different ligands would associate with chicken TTR and human TTR.

The component accounting for the yellow color observed in the TTR-containing peak isolated from the phenyl-sepharose column in Method 2 showed an absorbance spectrum similar to the pterin derivative, 7,8-dihydropterin-6-carboxaldehyde, which was found to be associated with TTR in Ernstrom's study (88). Pterin, the 2-amino, 4-hydroxy derivative of pteridine was named from its identification in the wings of butterflies. Plants can use pterin, p-aminobenzoate (PABA), and glutamate moieties to synthesize folates (115). Folates are essential cofactors for one-carbon transfer reactions in all organisms. However, our results showed that all 3 peaks isolated by using hydrophobic interaction chromatography were associated with yellow components which have similar absorbance spectra. Thus our results suggested the possibility of nonspecific association. The 7,8-dihydropterin-6-carboxaldehyde 
(yellow color) is know to be formed by photochemical degradation of biopterin (uncolored) under anaerobic conditions (116). In Ernstrom's study (88), they reported this yellow component was highly unstable and rapidly degraded to uncolored compounds when exposed to air. That may also explain why we did not observe yellow color in TTR after the final purification step using affinity chromatography. This unstable component may have degraded during this additional purification step. Alternatively, the yellow pigment may have been associated with protein contaminants that were removed during the final purification.

\section{GENERAL CONCLUSION}

Lutein and zeaxanthin are carotenoids present in a wide variety of vegetables and fruits. They are found particularly in green leafy vegetables such as spinach, collards, and kale. Lutein and zeaxanthin are more polar than many other carotenoids due to the presence of hydroxyl groups on the cyclic ring structure. Unlike the provitamin A carotenoids ( $\alpha$ carotene, $\beta$-carotene, and cryptoxanthin), they cannot be converted to vitamin $A$ in mammals. Mammals are not biochemically capable of biosynthesizing carotenoids. Carotenoids present in blood and tissues originate from the diet.

Growing epidemiological and clinical evidence suggests that lutein and zeaxanthin have protective effects against some chronic disease, particularly against eye diseases. In order to fully understand how lutein may benefit human health, a mechanistic understanding of the metabolism of lutein when ingested by humans in physiological amounts is needed. In this study, we used a biosynthetic ${ }^{13} \mathrm{C}$-lutein tracer and gas chromatography-combustion interfaced-isotope ratio mass spectrometry (GCC-IRMS) to investigate whether TTR could 
serve as a selective transport protein for lutein in human plasma and could thereby account for the selective accumulation of lutein in the human macula. The sensitivity of GCC-IRMS together with use of a stable tracer enabled us to detect a minute amount of lutein if bound to our hypothesized transport protein, transthyretin.

This study was challenging due to the difficult, laborious, and time-consuming isolation of ${ }^{13} \mathrm{C}$-Iutein tracer and plasma TTR and RBP in high purity. In this study, we successfully purified and crystallized ${ }^{13} \mathrm{C}$-labeled lutein from crude lipid extract of ${ }^{13} \mathrm{C}$-labeled algae. The purity of our ${ }^{13} \mathrm{C}$-labeled lutein tracer was $96.5 \%$ with $3.5 \%$ zeaxanthin and no $\beta$-carotene. Also, in this study, both TTR and RBP were purified in homogeneity from human plasma. TTR-sepharose affinity column and RBP-sepharose affinity column were packed in our lab. The affinity columns were used repeatedly during a period of 10 months without any sign of degradation or loss of binding capacity.

We found no ${ }^{13} \mathrm{C}$-lutein enrichment in the pure TTR extract. This result indicated that lutein is not associated with TTR (either RBP-bound TTR or free TTR) in human plasma after ingestion in physiological amounts. Some hydrophobic compounds with yellow color may bind to human TTR in the plasma. However, this association needs to be further proved by showing specificity. It might be interesting to attempt to purify TTR directly from serum by RBP-affinity chromatography without any prior purification. However, this would require a large amount of RBP to pack the affinity column. Given that RBP occurs only in small amounts $(40 \mathrm{mg} / \mathrm{L})$ in human plasma, the purification work would be very time consuming.

Our study provides new insight into carotenoid-binding protein studies using a stable isotope tracer method combined with the high precision of GCC-IRMS. Previous studies in 
carotenoid-binding proteins usually employed exogenous radioactive carotenoids which may not be applied in human study. In the study of retinal membrane proteins, XBP were only partially purified (64). Co-elution with endogenous carotenoids cannot prove the specific association between proteins and carotenoids. Future studies should be conducted to obtain highly purified proteins and evidence of their specific association with carotenoids. The methods we described above may be applied in the investigation of either lutein-specific plasma transport proteins or retinal membrane-associated binding proteins.

\section{ACKNOWLEDGEMENTS}

First of all, I would like to give my appreciation to my major professor, Dr. Wendy White. I will thank her not only for providing me financial support though out my graduate study, but also for her tremendous help in my study and research.

I also want to thank Dr. Louisa Tabatabai, Dr. Manju Reddy, and Dr. Mark Kaiser for being members of my graduate study committee. I really appreciate their help and time in my research studies and thesis work.

I would like to give special thanks to Ms Xixuan Hu, a Ph.D. candidate in our research lab, for teaching me the techniques and skills of running HPLC, isolating ${ }^{13} \mathrm{C}$-lutein tracer, and conducting the hydrogenation reaction and GCC-IRMS analysis. I also want to thank Ms Jeanne Stewart for her important cooperation in my research work.

I want to thank Dr. Lee Alekel for her generous help when I had a difficult time in my life. Also, I appreciate Dr. Murray Kaplan, Dr. Grace Marquis, Dr. Kevin Schalinske and all other faculty members in our department for their help. I also want to thank all my fellow 
graduate students in our department for their great friendship during my study in lowa State University.

At this moment of finishing my study and work in Iowa State University, I want give my thanks from my deep heart to my parents and sister for their tremendous emotional support and encouragement to help me complete my graduate study.

This study was supported by lowa State University Center for Advanced Technology Development (CATD) and Kemin Foods (Des Moines, IA, USA). We thank the Blood Bank of Mary Greeley Hospital (Ames, LA, USA) for supplying outdated human plasma. The technical assistance of Jeanne Stewart, Gretchen Zitterich (RN), and the staff of the Iowa State University Protein Facility is gratefully acknowledged. We also thank Dr. David Ong, Dr. Susan Gentleman, and Dr. Barbara Wiggert for their generous help in this study.

\section{REFERENCES}

1. Hyman, L. (1992) Epidemiology of AMD. In “Age-related macular degeneration: principles and practice". (G.R. Hampton and D.T. Nelson, eds). pp. 1-35. Raven Press, New York.

2. Klein, R., Klein, B., Linton, K.L.P. (1992) Prevalence of age-related maculopathy: the Beaver Dam Study. Ophthalmol. 99: 933-943.

3. U.S. Department of Commerce. Statistical Abstract of the United States 1995. (1995) U.S. Bureau of the Census, Current Population Report. pp. 25-1104. 
4. Bird, A. C. (1992) Pathophysiology of AMD. In "Age-related Macular Degeneration: Principles and Practice" (Hampton, G. R. and Nelson, P. T., eds). pp. 63-84. Raven Press, New York.

5. Bird, A. C., Bressler, N. M., Bressler, S. B., Chisholm, I. H., Coscas, G., Davis, M. D., Jog, P. T. V. M., Klaver, C. C. W., Klein, B. E. K., Klein, R., Mitchell., P., Sarks, J. P., Sarks, S. H., Sourbrane, G., Taylor, H. R., and Vingerling, J. R. (1995) An international classification and grading system for age-related maculopathy and age-related macular degeneration. Surv. Ophthalmol. 39: 367-374.

6. Macular Photocoagulation Study Group. (1986) Argon laser photocoagulation for neovascular maculopathy. Arch. Ophthalmol. 104: 494-701.

7. Macular Photocoagulation Study Group. (1990) Persistent and recurrent neovascularization after krypton laser photocoagulation for neovascular lesions of agerelated macular degeneration. Arch. Ophthalmol. 108:825-831.

8. Cruickshanks, K. J., Klein, R., Klein, B. E. K. (1993) Sunlight and age-related macular degeneration. Arch. Ophthalmol. 111: 514-518.

9. Eye Disease Case-Control Group. (1993) Antioxidant status and neovascular age-related macular degeneration. Arch. Ophthalmol. 111: 104-109.

10. Foote, C. S. (1976) Photosensitized oxidation and singlet oxygen: consequence in biological system. In "Free radicals in biology" (Pryor, W.A., ed.) Academic Press, New York. 2: 85-133.

11. Young, R.W. (1988) Solar radiation and age-related macular degeneration. Surv. Ophthalmol. 32: 252-269. 
12. Bone, R.A., Landrum, J. T., and Tarsis, S. L. (1985) Preliminary identification of the human macular pigment. Vis. Res. 25: 1531-1535.

13. Bone, R. A., Landrum, J. T., Fernandez, L., Tarsis, S. L. (1988) Analysis of the macular pigment by HPLC: Retinal distribution and age study. Invest. Ophthalmol. Vis. Sci. 29: 843-849.

14. Bone, R. A., and Landrum, J. T. (1992) Distribution of the macular pigment components, zeaxanthin and lutein in human retina. Methods Enzymol. 213: 360-366. Academic Press, San Diego.

15. Sommerburg, O. G, Siems, W. G., Hurst, J. S., Lewis, J. W., Kliger, D. S., and Kuijk, F. J. (1999) Lutein and zeaxanthin are associated with photoreceptors in the human retina. Curr. Eye. Res. 19: 491-495.

16. Rapp, L. M., Seema, S. S., and Choi, J. H. (2000) Lutein and zeaxanthin concentrations in rod segment membranes from perifoveal and peripheral human retina. Invest. Opthalmol. Vis. Sci. 41: 1200-1209.

17. Schmitz, H. H., Poor, C. L., Gugger, E. T., and Erdman, J. W. Jr. (1993) Analysis of carotenoids in human and animal tissues. Methods Enzymol. 214:102-16.

18. Walls, G.L. (1967) "The Vertebrate Eye and Its Adaptive Radiation" Hafner, New York.

19. Reading, V. M., and Weale, R. A. (1974) Macular pigment and chromatic aberration. J. Opt. Soc. Am. (A) 64: 231-234.

20. Hammond, B. R., Wooten, B. R. Jr., and Curran-Celetano, J. (2001) Carotenoids in the retina and lens: possible acute and chronic effects on human visual performance. Arch. Biochem. Bioph. 385: 41-46. 
21. Landrum, J. T., Bone, R. A., Kilburn, M. D. (1997) The macular pigment: a possible role in protection from age-related macular degeneration. Adv. Pharmacol. 38: 537-556.

22. Kirshfeld, K. (1982) Carotenoids pigments: Their possible role in protecting against photooxidation in eyes and photoreceptor cells. Proc. R. Soc. Lond. (Biol.) 216: 71-85.

23. Bone, R. A., and Landrum, J.T. (1984) Macular pigment in Henle fiber membranes: A model for Haidinger's brushes. Vis. Res. 24: 103-108.

24. Snodderly, D. M. (1995) Evidence for protection against age-related macular degeneration by carotenoids and antioxidant vitamins. Am. J. Clin. Nutr. 62(Supp1.): 1448S-1461S.

25. Schalch, W., Dayhaw-Barker, P., and Barker, F. M. (1999) The carotenoids of the human retina. In "Nutritional and Environmental Influences on Eye. (Taylor, A., ed.) pp. 215-225. CRC Press. Boca Raton, CA, USA.

26. Bernstein, P. S., Khachik, F., Carvalho, L. S., Muir, G. J., Zhao, D.Y, and Katz, N. B. (2001) Identification and quantitation of carotenoids and their metabolites in the tissues of the human eye. Exp. Eye Res. 72: 215-223.

27. Goldberg, J., Flowerdew, G., Smith, E., Brody, J. A., and Tso, M. O. M. (1988) Factors associated with age-related macular degeneration: an analysis of data from the First National Health and Nutrition Examination Survey. Am. J. Epidemiol. 128: 700-710.

28. West, S., Vitale, S., and Hallfrisch, J. (1994) Are antioxidanta or supplements protective of age-related macular degeneration? Arch. Ophthamol. 112: 222-227.

29. Seddon, J. M., Ajani, U. A., Sperduto, R. D., Hiller, R., Blair, N., Burton, T. C., Farber, M. D., Gragoudas, E. S., Haller, J., Miller, D. T., Yannuzzi, L.A., and Willett, W. (1994) 
For the Eye Disease Case Control Study Group: Dietary carotenoids, vitamin A, C, and E, and advanced age-related macular degeneration. JAMA 272: 1413-1420.

30. Feeney-Burris, L., Neuring, M., and Gao, C. L. (1989) Macular pathology in monkeys fed semipurified diets. Prog. Clin. Biol. Res. 314: 601-622.

31. Hammond, B. R., Wooten, B. R, and Snodderly, D. M. (1997) Individual variations in the spatial profile of human macular pigment. J. Opt. Soc. Am. A. 14: 1187-1196.

32. Hammond, B. R., Wooten, B. R, and Snodderly, D. M. (1998) Preservation of visual sensitivity of old subjects: association with macular pigment sensity. Inves. Ophthamol. Vis Sci. 39: 397-406.

33. Bone, R. A., Landrum, J. T., Mayne, S. T., Gomez, C. M. (2001) Macular pigment in donor eyes with and without AMD: A case-control study. Inves. Ophthamol. Vis Sci. 42: $235-240$.

34. Yeum, K. J., Booth, S. L., Sadowski, J. A., Liu, C., Tang, G., Krinsky, N. I., Russell, R. M. (1996) Human plasma carotenoid response to the ingestion of controlled diets high in fruits and vegetables. Am. J. Clin. Nutr. 64: 596-602

35. Landrum, J. T., Bone, R. A., Joa, H., Kilburn, M.D., Moore, L. L., Sprague, K. E. (1997) A one year study of the macular pigment: the effect of 140 days of a lutein supplement. Exp. Eye Res. 65(1): 57-62.

36. Hummond, B. R., Johnson, E. J., Russell, R. M., Krinsky, N. I., Yeum, K. J., Edwards, R. B., and Snodderly, D. M. (1997) Dietary modification of human macular pigment density. Inves. Ophthamol. Vis Sci. 38: 1795-1801. 
37. Handelman, G. J., Nightingale, Z. D., Lichtenstein, A. H., Schaefer, E. J., Blumberg, J. B. (1999) Lutein and zeaxanthin concentrations in plasma after dietary supplementation with egg yolk. Am. J. Clin. Nutr. 70: 247-251.

38. Johnson, E. J., Hanmond, B. R., Yeum, K. J., Qin, J., Wang, X. D., Castaneda, C., Snodderly, D. X., and Russell, R. M. (2000). Relation among serum and tissue concentrations of lutein and zeaxanthin and macular pigment density. Am. J. Clin. Nutr. 71: 1555-1562.

39. Rich, S. (1999) ARMD--pilot (case series) environmental intervention data. J. Am. Optom. Assoc. 70(1):24-36.

40. Dagnelie, G., Zorge, I. S., and McDonald, T. M. (2000) Lutein improves visual function in some patients with retinal degeneration: a pilot study via the internet. J. Am. Optom. Assoc. 71: 147-164.

41. Olmedilla, B., Granado, F., Blanco, I., Vaquero, M., and Cajigal, C. (2001) Lutein in patients with cataracts and age-related macular degeneration: a long-term supplementation study. J. Sci. Food Agric. 81: 904-909.

42. Mares-Perlman, J. A., Klein, R. Klein, B. E. K., Greger, J. L., Brady, W. E., Palta, M., and Rittrt, L. L. (1996) Association of zinc and antioxidant nutrients with age-related maculopathy. Arch. Ophthalmol. 114: 991-997.

43. Mares-Perlman, J. A., Brady, W. E., Klein, R. Klein, B. E. K., Boean, P., StacewiczSapuntzakis, M., and Palta, M. (1995) Serum antioxidants and age-related degeneration in a population based case control study. Arch. Ophthalmol. 113: 1518-1523.

44. VandenLangenberg, G. M., Mares-Perlman, J. A., Klein, B. E. K., Bady, W. E., Palta, M. (1998) Association between antioxidant and zinc intake and the 5 year incidence of . 
early age-related maculopathy in the Beaver Dam Eye Study. Am. J. Epidemiol. 148: 204-214.

45. Sanders, T. A. B., Haines, A. P., Wormald, R. Wright, L. A., Obeid, O. (1993) Essential fatty acids, plasma cholesterol, and fat-soluble vitamins in subjects with age-related maculopathy and matched control subjects. Am. J. Clin. Nutr. 57: 428-433.

46. Handelman, G. J., Dratz, E. A., Reay, C. C., van KuijK, F. J. (1988) Carotenoids in the human macula and whole retina. Invest. Ophthalmol. Vis. Sci. 29: 850-855.

47. Yeum, K. J., Taylor, A, Tang, G., and Russell, R. M. (1995) Measurement of carotenoids, retinoids, and tocopherols in human lens. Invest. Ophthalmol. Vis. Sci. 36: 2756-2761.

48. Bernstein, P. S., Khachik, F., Carvalho, L. S., Muir, G. J., Zhao, D., and Katz, N. B. (2001) Identification and quantitation of carotenoids and their metabolites in tissues of human eye. Exp. Eye Res. 72: 215-223.

49. Gao, G., Wei, C. C., Jeevarajan, A. S., and Kispert, L. D. (1996) Geometrical isomerization of carotenoids mediated by cation radical/dication formation. J. Phys. Chem. 100: 5362-5366.

50. Khalid, M., Hadjipetou, A. S., and Kispert, L. (1990) Electrochemical and electron paramagnetic resonance studies of carotenoid cation radicals and dications: effect of deuteration J. Phys. Chem. 94: 5164-5169.

51. Mares-Perlman, J. A., Fisher, A., Klein, R., Palta, M., Block, G., Millen, A. E., and Wright, J. D. (2001) Lutein and zeaxanthin in the diet and serum and their relation to age-related maculopathy in the third National Health and Nutrition Examination Survey. Am. J. Epidemiol. 153: 424-432. 
52. Mangels, A. R., Holden, J. M., Beecher, G. R., Forman, M. R., and Lanza, E. (1993) Carotenoid content of fruits and vegetables: an evaluation of analytic data. J. Am. Diet. Assoc. 93: 284-296.

53. U.S. Department of Agriculture, Agriculture Research Service. (1998) U.S.D.A. nutrition database for stsndard reference, release 12. Nutrient data laboratory homepage, http:// www.nal.usda.gov/fnic/foodcomp.

54. Herreo, C., Chen, Y., Chi, J., Bone, R. A., and Landrum, J. Y. (2000) Lutein metabolism in human serum and retina. FASEB J. 14, A234 (abstract 167.7).

55. Bone, R. A., Landrum, J. T., Dixon, Z., Chen, Y., Llerena, CM. (2000) Lutein and zeaxanthin in the eyes, serum and diet of human subjects. Exp Eye Res. 71(3): 239-245.

56. Brady, W. E., Mares-Perlman, J. A., Bowen, P., and Stacewicz-Sapuntzakis, M. (1996) Human serum carotenoid concentrations are related to physiology and lifestyle factors. J. Nutr. 26: 129-136.

57. Rock, C. L., Thornquist, M. D., Neuhouser, M. L., Kristal, A. R., Neumark-Sztainer, D., Cooper, D. A., Patterson, R. E., and Cheskin, L. J. (2002) Diet and lifestyle correlates of lutein in the blood and diet. J. Nutr. 132: 525S-530S.

58. Lakshman, M. R. and Okoh, C. (1993) Carotenoid-protein complex. Methods Enzymol. 214: 74-86.

59. Reddy, K. J., Bullerjahn, G. S., and Sherman, L. A. (1993) Characteristics of membraneassociated carotenoid-binding proteins in cyanobacteria and prochlorophytes. Methods Enzymol. 214: 390-401. 
60. Zagalsky, P. F. (1995) Carotenoproteins. In carotenoids: isolation and analysis. Vol. 1 A. (Britton, G., Liaaen-Jensn, S., and Pfander, H., eds). pp. 287-294. Birkhauser-Verlag: Basel, Switzerland).

61. Jouni, Z. E. and Wells, M. A. (1996) Purification and partial characterization of the lutein-binding protein from the midgut of the silkworm Bombyx mori. J. Biol. Chem. 271: $14722-14726$.

62. Rao, M. N., Ghosh, P., and Lakshman, M. R. (1997) Purification and partial characterization of a cellular carotenoid-binding protein from ferret liver. J. Biol. Chem. 272: $24450-24460$.

63. Berstein, P. S., Balashov, N. A., Tsong, E. D., and Rando, R. R. (1997) Retinal tubulin binds macular carotenoids. Inv. Ophthalmol. Vis. Sci. 38: 167-175.

64. Yemelyanov, A. Y., Katz, N. B., Bernstein, P. S. (2001) Ligand-binding characterization of xanthophyll carotenoids to solubilized membrane proteins derived from human retina. Exp. Eye Res. 72 (4): $381-392$.

65. Clevidence, B. A., and Bieri, J. G. (1993) Association of carotenoids with human plasma lipoproteins. Methods Enzymol. 214: 33-46.

66. Erdman, J. W., Bierer, T. L., Gugger, E. T. (1993) Absorption and transport of carotenoids. Ann. N.Y. Acad. Sci. 691: 76-85.

67. Khachik, F., Spangler, C. J., Smith, J. C. Jr., Canfield, L. M., Steck, A., Pfander, H. (1997) Identification, quantification, and relative concentrations of carotenoids and their metabolites in human milk and serum. Anal. Chem. 69: 1873-1881. 
68. Pettersson, T., Emstrom, U., Griffiths, W., Sjovall, J., Bergman, T. (1995) Lutein associated with a transthyretin indicates carotenoid derivation and novel multiplicity of transthyretin ligands. FEBS Letters 365:23-26.

69. Duan, W., Achen, M. G., Richardson, S. J., Lawrence, M. C., Wettenhall, R. E. H., Jaworowski, A., and Schreiber, G. (1991) Isolation, characterization, cDNA cloning and gene expression of an avian transthyretin. Implications for the evolution of structure and function of transthyretin in vertebrates. Eur. J. Biochem. 200: 679-687.

70. Black, C. C. F., Geisow, M. J., Oatley, S, J., Rerat, B., and Rerat, C. (1978) Structure of prealbumin: Secondary, terliary and quaternary ineractions determined by Fourier refinement at 1.8 §. J. Mol. Biol. 121: 339-356.

71. Robbin, J., Cheng, S. Y., Gershengorn, M. C., Glinoer, D., Cahnmann, H. J., Edelhoch, H. (1978) Thyroxine transport proteins of plasma: molecular properties and biosynthesis. Rec. Prog. Horm. Res. 34: 477

72. Ingbar, S. H. (1958) Endocrinology. 63: 256-259.

73. Kanai, M., Raz, A., and Goodman, D. S. (1968) Retinol-binding protein: the transport protein for vitamin A in human plasma. J. Clin. Invest. 47: 2025-2044.

74. Bridges, C. D. B. (1984) In "The Retinoids". (Sporn, M. B., Roberts, A. B., and Goodman, D. S., eds.) Vol. 2. pp 125-176. Academic Press, New York.

75. Blomhoff, R., Green, M. H., Berg, T., and Norum, K. R. (1990) Transport and storage of vitamin A. Science 250: 399-404.

76. Bok, D., and Heller, J. (1976) Transport of retinol from the blood to the retina: an autoradiographic study of the pigment epithelial cell surface receptor for plasma retinolbinding protein. Exp. Eye Res. 22: 395. 
77. Heller, J. (1975) Interactions of plasma retinol binding protein with its receptor: specific binding of bovine and human retinol binding protein to pigment epithelial cells from bovine eyes. J. Biol. Chem. 250: 3613-3619.

78. Bunt-Milam, A. H, and Saari, J. C. (1983) Immunocytochemical localization of two retinol-binding proteins in vertebrate retina. J. Cell Biol. 97: 703-712.

79. Felding, P., and Fex, G. (1982) Cellular origins of prealbumin in the rat. Biochim. Biophys. Acta. 716: 446-449.

80. Soprano, D. R., Herbert, J., Soprano, K. J., Schon, E. A., and Gooman, D. S. (1985) Demonstration of transthyretin mRNA in the brain and other extraheptic tissues in the rat. J. Biol. Chem. 260: 11793-11798.

81. Dickson, P. W., Aldred, A. R., Marley, P. D. Tu, G. F., Howlett. G. J. and Schreiber, G. (1985) High prealbumin and transferrin mRNA levels in the choroid plexus of rat brain. Biochem. Biophys. Res. Commun. 127: 890-895.

82. Dickson, P. W., Aldred, A. R., Marley, P. D., Bannister, D., and Schreiber, G. (1986) Rat choroid plexus specializes in the synthesis and secretion of transthyretin (prealbumin): regulation of transthyretin synthesis in choroids plexus is independent from that in liver. J. Biol. Chem. 261: 3475-3479.

83. Dwork, A. J., Cavallaro, T., Martone, R., Goodman, D. S., Schon, E. A., and Herbert, J. (1990) Distribution of transthyretin in the rat eye. Invest. Ophthalmol. Vis. Sci. 31: 489496.

84. Cavallaro, T., Martone, R. Dwork, A. J., Schon, E. A., and Herbert, J. (1990) The retinal pigment epithelium is the unique site of transthyretin synthesis in the rat eye. Invest. Ophthalmol. Vis. Sci. 497-501. 
85. Herbert, J., Cavallaro, R., and Martone, R. (1991) The distribution of retinol-binding protein and its mRNA in the rat eye. Invest. Ophthalmol. Vis. Sci. 32. 302-309.

86. Ong, D. E., Davis, J. T., O’Day, W. T., and Bok, D. (1994) Synthesis and secretion of retinol-binding protein and thranstyretin by cultured retinal pigment epithelium. Biochemistry. 33: 1835-1842.

87. Gaur, V. P., De Leeuw, A. M., Milam, A. H., and Saari, J. C. (1990) Localization of cellular retinoic acid-binding protein to amacrine cells of rat retina. Exp. Eye. Res. 50: 505-511.

88. Ernstrom, U., Pettersson, T., Jornvall, H. (1995) A yellow component associated with human transthyretin has properties like a pterin derivative, 7,8-dihydropterin-6-

89. carboxaldehyde. FEBS Letters 360: 177-182.

90. Marusich, W. L. and Bauernfeind, J.C. (1981) Oxycarotenoids in poultry feeds. In "Carotenoids as colorants and vitamin A precursors" (JC Bauemfeind, ed.). New York, NY, Academic Press. pp. 319-462.

91. Dueker, S. R., Jones, A. D., Smith, G. C., and Clifford, A. (1994) Stable isotope methods for the study of $\beta$-carotene- $\mathrm{d}_{8}$ metabolism in human utilizing tandem mass spectrometry and high-performance liquid chromatography. J. Anal. Chem. 66: 4177-4185.

92. Tobias, H. and Brenna, J. T. (1996) High-precision D/H measurement from organic mixture by gas chromatography continuous-flow isotope ratio mass spectrometry using a palladium filter. Anal. Chem. 68: 3002-3007.

93. Parker, R. S., Swanson, J. E., Marmor, B., Goodman, K. J., Spielman, A. B., Brenna, J. T., Viereck, S. M., and Canfield, W. K. (1993) Study of beta-carotene metabolism in 
humans using $13 \mathrm{C}-$ beta-carotene and high precision isotope ratio mass spectrometry. Ann. N.Y. Acad. Sci. 691: 86-95.

94. You, C. S., Parker, R. S., Goodman, K. J., Swanson, J. E., and Corso, T. N. (1996) Evidence of cis-trans isomerization of 9-cis-beta-carotene during absorption in humans. Am. J. Clin. Nutr. 64: 177-183.

95. Liang, Y., White, W. S., Yao, L., and Serfass, R. E. (1998) Use of high-precision gas isotope ratio mass spectrometry to determine natural abundance ${ }^{13} \mathrm{C}$ in lutein isolated from $\mathrm{C}_{3}$ and $\mathrm{C}_{4}$ plant sources. J. Chromatogr. A. 800: 51-58.

96. Yao, L., Liang, Y., Trahanovsky, W., S., Serfass, R. E., and White, W. S. (2000) Use of $\mathrm{a}^{13} \mathrm{C}$ tracer to quantify the plasma appearance of a physiological dose of lutein in humans. Lipids 35: 339-348.

97. Khachik, G., Englert, G., Beecher, G. R., and Smith Jr., J. C. (1995) Isolation, structural elucidation, and partial synthesis of lutein dehydration products in extracts from human plasma. J. Chromatogr. B 670(2): 219-33.

98. You, C. S., Parker, R. S., Goodman, K. J., Swanson, J. E., and Corso, T. N. (1996) Evidence of cis-trans isomerization of 9 -cis- $\beta$-carotene during absorption in humans. Am. J. Clin. Nutr. 64: 177-183.

99. Kanda, Y., Goodman, D. S., Caufield, R. E., and Morgan, F. J. (1974) The amino acid sequence of human plasma prealbumin. J. Biol .Chem. 249: 6796-6805.

100.Goodman, D. S. (1984) In "The Retinoids" (Sporn, M. B., Robberts, A. B., and Goodman, D. S., eds) Vol 2, pp: 41. Academic Press, Orlando, Florida, 101.Peterson, P. A. (1971) Studies on the interaction between prealbumin, retinol-binding protein, and vitamin A. J. Biol. Chem. 246: 44-49. 
102.van Jaarsveld, P. P., Edelhoch, D. S., Goodman. D. S., and Robbins, J. (1973) The interaction of human plasma retinol-binding protein and prealbumin. J. Biol. Chem. 248: 4698-4705.

103.Blaner, W. S. and Goodman, D. S. (1999) Purification and properties of plasma retinolbinding protein. Methods Enzymol. 189: 193-207.

104.Berni, R., Ottonello, S., and Monaco, H. (1985) Purification of human plasma retinolbinding protein by hydrophobic interaction chromatography. Analytical Biochemistry 150: $273-277$.

105.Vahlquist, A., Nilsson, S. F., and Petersson, P. A. (1971) Ioslation of human retinol binding protein by affinity chromatography. Eur. J. Biochem. 20: 160-168.

106.Fex, G., Laurell, C., and Thulin, E. (1977) Purification of prealbumin from human and canine serum using a two-step affinity chromatographic procedure. Eur. J. Biochem. 75: $181-186$.

107.Rylander, P. (1979) Catalytic hydrogenation in organic syntheses. Academic Press.

108.Johnson, E. A. and Schroeder, W. A. (1995) Microbial carotenoids. In "Advances in Biochemical Engineering Biotechnolgy". 53: 120-177.

109.Abe, T., Muto, Y., and Hosoya, N. (1975) Vitamin A transport in chicken plsma: isolation and characterization of retinol-binding protein (RBP), prealbumin (PA), and RBP-PA complex. J. Lipid. Res. 16: 200-210.

110.Power, D. M., Elias, N. P., Richardson, S. J., Mendes, J., Soares, C. M., and Santos, C. R. (2000) Evolution of the thyroid hormone-binding protein, thransthyretin. Gen. Comp. Endocrinol. 119: 241-255. 
111.Sunde, M., Richardson, S. J., Chang, L., Pettersson, T. M., Schreiber, G., and Blake, C. C. (1996) Eur. J. Biochem. 236: 491-499.

112.Chang, L., Munro, S. L., Richardson, S. J., and Schreicer, G. (1999) Evolution of thyroid hormone binding by transthyretins in birds and mammals. Eur. J. Biochem. 259: 534542.

113.Monaco, H. L., Rizzi, M., and Coda, A. (1995) Structure of a complex of two plasma proteins: transthyretin and retinol-binding protein. Science 268: 1039-1041.

114.Griffin, H., Acamovic, F., Guo, K., and Peddie, J. (1989) Plasma lipoprotein metabolism in lean and in fat chickens produced by divergent selection for plasma very low density lipoprotein concentration. J. Lipid Res. 30: 1243-1250.

115.Larsson, M., Pettersson, T., and Carlstrom. A. (1985) Thyroid hormone binding in serum of 15 vertebrate species: isolation of thyroxine-binding globulin and prealbumin analogs. Gen. Comp. Endocrinol. 58: 360-75.

116.Hanson, A. D. and Gregory J. F. (2002) Synthesis and turnover of folates in plants. Curr. Opin. Plant Biol. 5: 244-249.

117.Maharaj, G., Selinsky, B. S., Appleman, J. R., Perlman, M., London, R. E., and Blakley, R. L. (1990) Dissociation constants for dihydrofolic acid and dihydrobiopterin and implications for mechanistic models for dihydrofolate reductase. Biochemistry. 29: $4554-4560$. 


\section{APPENDIX}

\section{SDS-PAGE}

1. Prepare running buffer

NuPage MOPS running buffer $50 \mathrm{~mL}$

Ultrapure water

Invert to mix.

Set aside $800 \mathrm{~mL}+200 \mathrm{~mL}$.

2.Prepare sample and Perfect protein standard solutions.

Sample or standard $30 \mu \mathrm{L}$

Ultrapure water $2.5 \mu \mathrm{L}$

LDS sample buffer $12.5 \mu \mathrm{L}$

Mix gently.

Add reducing agent $5 \mu \mathrm{L}$

Mix gently.

Heat $10 \mathrm{~min}$ at $70^{\circ}$.

Centrifuge briefly (about $1 \mathrm{~min}$ ) in microcentrifuge.

Do not place samples on ice.

3. Prepare the gel.

Cut open the pouch and remove the NuPage gel.

Rinse the gel cassette with d. water. *Peel off the tape from the bottom of the cassette.

In one smooth motion, gently pull the comb out of the cassette.

Use an automatic pipette to rinse the sample wells with running buffer. Invert the gel and shake to remove the buffer. Repeat two more times.

Orient 2 gels in the Mini-cell so that the notched "well" side faces inward toward the buffer core.

If you are running one gel, the plastic buffer dam replaces the second gel cassette.

Lock into place with the cam.

*Add $500 \mu \mathrm{L}$ of NuPage Running Buffer Antioxidant to $200 \mathrm{~mL}$ of running buffer. Invert to mix.

Fill the inner buffer chamber with $200 \mathrm{~mL}$ of running buffer.

Fill the outer buffer chamber with $800 \mathrm{~mL}$ of running buffer.

4. Load the gel.

For 10 wells ( $1 \mathrm{~mm}$ thickness), load $25 \mu \mathrm{L}$ for samples and $5 \mu \mathrm{L}$ for Perfect Protein marker.

5. Run the gel.

With the power turned off, plug the black and red leads into the power supply.

Run at $200 \mathrm{~V}$ for $\sim 55 \mathrm{~min}$.

Shut off the power. 
Disconnect electrodes.

Remove gel.

\section{TRANSFER}

1. Prepare the transfer buffer.

Prepare $1 \mathrm{~L}$ Tris Glycine buffer according to the directions on the bottle (don't need nanopure water). *Don't use Tris Glycine SDS buffer.

2. Prepare the gel.

Separate the 3 bonded sides of the gel with the gel knife. (The well side of the gel should face up.)

Carefully remove and discard the top plate allowing the gel to remain on the bottom plate.

Use a razor to cut off the bottom lip of the gel ( 3 cuts initially).

Cut the bottom right-hand comer of the gel.

Flip the gel and wash for 5-10 min in buffer while set up the transfer.

3. Prepare the membrane and blotting paper.

*Cut nitrocellulose (Protran for protein) membrane at bottom right edge with scissors. Label edge of membrane using Skillcraft pen.

Need 8 sheets of $3 \mathrm{~mm}$ paper for 2 gels.

Use about $700 \mathrm{~mL}$ of transfer buffer to soak the pads, paper, and membranes.

Assemble on the dark surface:

Scotchbrite pad

2 layers $3 \mathrm{~mm}$ paper

Flip gel (cut edge is now lower left corner.) Combs face straight edge.

Nitrocellulose membrane (writing faces gel)

Roll with glass pasteur pipette to remove excess buffer.

2 layers $3 \mathrm{~mm}$ paper

Roll with glass pasteur pipette to remove excess buffer.

Scotchbrite pad

Clear surface.

Clamp (slides) together.

4. Transfer

Fill the inner chamber until the gel/membrane sandwich is just covered with transfer buffer. Don't fill all the way to the top; this will only generate extra conductivity and heat.

Fill the outer buffer chamber with transfer buffer.

Load frosted chamber with ice to prevent overheating.

With the power turned off, plug the black and red leads into the power supply.

Set power supply at $200 \mathrm{~V}$ for 1.5 hours. 


\section{IMMUNOBLOT}

1. Prepare blocking solution (TIBS, $3 \% \mathrm{BSA}$ ).

$7.5 \mathrm{~mL}$ BSA ( $20 \%$ solution)

$42 \mathrm{~mL}$ (20X wash solution, TIBS - KPL)

**Handle membrane with forceps.

2. Stain membrane with $0.1 \%$ Ponceau S. (in $1 \%$ acetic acid)

Approximately $5 \mathrm{~min}$ on shaker.

Rinse with $d$. water.

Don't let blots dry.

3. Block

Rinse membrane with TIBS-3\% BSA for $1 \mathrm{~h}$ (cover with parafilm).

Remark membrane to indicate which antibody. Blot with Kimwipe before writing with Skillcraft pen.

4. Add primary antibody.

Keep antibody on ice.

Dilute antibody $(1: 1000=5 \mu \mathrm{L}$ in $5 \mathrm{~mL}$ for HIS tag or 1:2000 $2.5 \mu \mathrm{L}$ in $5 \mathrm{~mL})$ in

TIBS-3\% BSA in conical plastic centrifuge tube with orange cap. Rinse pipette tip in solution.

Use smallest possible tray. Label trays with tape.

Add $5 \mathrm{~mL}$ antibody solution.

Incubate on shaker ( $1 \mathrm{~h}$ to overnight).

5. Wash with TIBS (NO BSA).

Keep membrane writing side up.

3 washes ( 5 min each)

6. Incubate with secondary antibody.

Dilute antibody $(3 \mu \mathrm{L}) 1: 10,000$ in $30 \mathrm{~mL}$ TIBS- $3 \%$ BSA.

Add $6 \mu \mathrm{L}$ S-tag (1:5,000 dilution).

Incubate membrane with antibody for 1 hour on shaker. Cover with parafilm.

7. Wash 3 times ( 5 min each) with TIBS (NO BSA).

8. Visualize.

Decant TIBS solution. Add BCIP/NBT substrate for alkaline phosphatase (brown bottle from freezer). 